Logan Clendening Lectures on the

History and Philosophy of

Medicine

Second Series

\title{
The Old Egyptian \\ Medical Papyri
}


Logan Clendening Lectures on the History and Philosophy of Medicine

\author{
Second Series
}

\title{
The Old Egyptian \\ Medical Papyri
}

\author{
by \\ Chauncey D. Leake \\ Vice-President, University of Texas-Medical Branch \\ Galveston
}

UNIVERSITY OF KANSAS PRESS, LAWRENCE, KANSAS - - - 1952 
Copyright, 1952, by the University of Kansas Press

All Rights Reserved

PRINTED IN THE U.S.A. BY THE UNIVERSITY OF RANSAS PRESS

LAWRENCE, KANSAS 


\section{Prefatory Note}

To follow John Fulton in offering the second series of Logan Clendening Lectures is a formidable task. Professor Fulton, now happily devoting his exceptional talents to the exploration of the complicated history of medicine, set a high standard for the annual lectures so appropriately established to maintain the stimulating intellectual interests of Logan Clendening.

It is a joy, however, to try to offer worthy tribute to Logan Clendening, for he was ever my cheerful and encouraging friend. Whether at the dramatic festivities of the Bohemian Grove, or at the exciting conversation of his hospitable table, or in the intellectual comfort of his fine library, or when facing the great treasures of the William Rockhill Nelson Art Gallery, Logan Clendening was to me always provocative, always witty and exciting, always friendly. His interest in our study of the Hearst Medical Papyrus prompts me to offer these sketchy and preliminary notes as a token of the high regard in which I hold his memory.

The studies here partially reported have been in progress for many years. They began a couple of decades ago at the University of California Medical Center in San Francisco. Stimulated by Breasted's monumental analysis of the Edwin Smith Surgical Papyrus which appeared in 1930, we became interested in the Hearst Medical Papyrus. This was exhibited at the time in the Archaeology Museum on Parnassus Heights. Doctor Henry F. Lutz, Professor of Semitic Languages, Doctor Sanford Larkey, then Professor of the History and Bibliography of Medicine, 
and I undertook the translation and annotation of this document.

In this we were ably helped by the patience of Miss Marjorie Williams, then secretary of the Pharmacology Laboratory at the University of California Medical Center. Among my most pleasant memories are those associated with the sessions we held together in the sheltering Redwoods at Pharmaglen in the Santa Cruz mountains. When we scattered a decade ago, our co-operative effort suffered. Last year, it was my good fortune to be privileged to continue the study of old Egyptian medical papyri under the auspices of the Institute for Advanced Study at Princeton. There the resources of the University Library greatly aided in an understanding of many previously puzzling problems, particularly those relating to drug measurement as indicated in the documents. There also was to be found that intellectual inspiration from the Director, Doctor J. Robert Oppenheimer, and his staff, which was most conducive to one's most earnest selfcritical endeavor. Grateful thanks are extended to Professor Otto Neugebauer for his personal interest and helpfulness.

Professor Lutz, Doctor Larkey, and myself have completed a preliminary translation and annotation of the Hearst Medical Papyrus. Our commentaries and discussions are now being critically examined and brought up to date, in the light of the many recent advances which have been made in appreciation of old Egyptian medicine. Reference will frequently be made to the many valiant scholars who have contributed so much to a realization of the significance of ancient Egyptian medical practice. Im- 
possible and inappropriate would it be in this sketchy review to offer technical detail about their meticulous analyses. The material summarized in this little volume has been prepared for the amusement of those who are interested generally in the development of medicine and science, rather than for the criticism of those who are either expert medical historians or Egyptologists. While the imperfections of the effort are quite apparent, it may nevertheless stimulate others to join the study of ancient medical practices. Such a study may be both enlightening and humbling.

Difficult has it been to select what may be most interesting and pertinent about old Egyptian medicine for the intelligent layman, physician, or medical student, from the abundance of detailed scholarly material available. Except for the expert, much of this is painfully dull and tiresome. The temptation was great to develop a reasonably comprehensive account of the drugs identified in the prescriptions of old Egyptian medical papyri. We have accumulated extensive notes on the Hearst Papyrus drugs, trailing many of them through Graeco-Roman writings and medieval formularies, until their systematic clinical and pharmacological analysis in modern times. To have included a discussion of these data would have been inappropriate to the scope of this effort. Apologies are thus offered for making generalizations on the matter without satisfactory evidence or documentation. When the Hearst Medical Papyrus is properly published with translation and commentary, this detailed material will be included.

It is a pleasure for me to acknowledge my indebtedness to Doctor Ralph Major of the University of Kansas School 
of Medicine for his encouragement and interest in this work. For many years my wife has patiently supported my endeavors with Egyptian medicine, and I am grateful for her help. My thanks are due to Miss Mary Jane Steding for her unfailing care and attention in the preparation of the manuscript of these lectures. To Professor Clyde K. Hyder of the University of Kansas Press special thanks are extended for his patient care in guiding this effort during publication.

C.D.L.

On the Strand, Galveston,

AprIL 10, 1951 


\section{Contents}

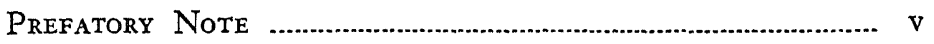

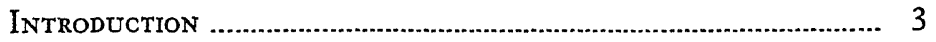

The Chief Egyptian Medical Papyri ..................................... 7

Old Egyptian Weights and Measures ................................... 18

Drug Measurement in the Old Egyptian Medical Papyri ........ 28

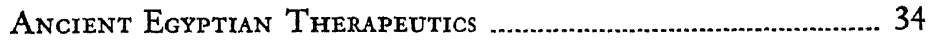

The Hearst Medical Papyrus ................................................... 47

Organization of the Hearst Medical Papyrus ........................... 50

Diseases in the Hearst Medical Papyrus .................................. 57

The Ingredients of the Hearst Papyrus Prescriptions ............. 68

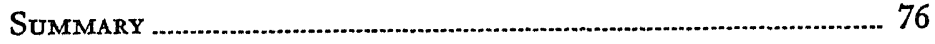

Appendix: List of Prescriptions in the Hearst Medical

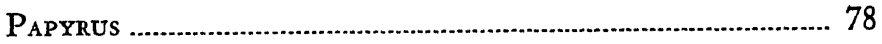

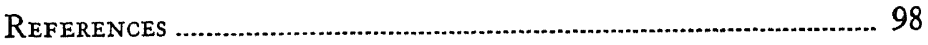

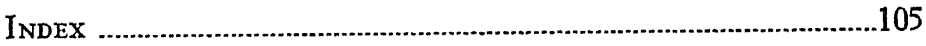




\section{Logan Clendening Lectures on the}

History and Philosophy of

MEDicine

Second Series

The Old Egyptian

Medical Papyri 


\section{Introduction}

I

$t$ is customary for anyone attempting to describe anything relating to Egypt to begin with a description of its geography. In his brilliant discussion of old Egyptian medicine, Henry Sigerist opens by quoting the ancient hymn to the Nile: "Praise to thee, O Nile, that cometh forth from the earth to nourish the dwellers in Egypt."

Will Cuppy is less reverent: "Egypt has been called the Gift of the Nile. Once every year the river overflows its banks, depositing a layer of rich alluvial soil on the parched ground. Then it recedes and soon the whole country-side, as far as the eye can reach, is covered with Egyptologists."

The results of old Egyptian research are exhausting. Yet, as summarized by S.R.K. Glanville and his associates, or by Wilson, they furnish a remarkably detailed picture of a great culture, the achievements of which still profoundly affect our own. Ancient Egyptian medicine is particularly well known, its popular characteristics by inference, and its professional achievements by study of the technical medical treatises preserved for us. Medical matters in old Egypt were thus contrasted by Sigerist into "magico-religious medicine" on the one hand, and "empirico-rational medicine," on the other. There is some question as to how far this distinction may be validated, then or now.

One might justify a contrast between the popular beliefs, fears, and superstitions about disease on the one hand, and professional medical theories and practices on the other. Such a contrast would probably be as valid for old Egypt as for modern Europe. Similarities in the con- 
trast might be quite evident. There was magic endeavor in approaching disease popularly in old Egypt just as there is now in our culture. On the other hand, there is clear evidence from the surviving documents of a rational professional effort toward the systematic analyses of diseased conditions and toward the application of empirical observation in their management. In this discussion the professional endeavor will be considered.

The old Egyptians apparently began to prolong memory by means of recordings as early as the third millennium before the Christian era. Spieser has proposed that the initial impetus to writing arose among the hardy Sumerian individualists in stamping their individual property with their personal seals. Interestingly he contrasts the subsequent developments for scientific endeavor in the relatively democratic Valley of the Euphrates, with the situation in the more authoritarian culture of the Valley of the Nile. Alan Gardiner and W. F. Albright skillfully advance the hypothesis that the Greek alphabet was derived from the Canaanites, who developed the principle from Egyptian hieroglyphics. From pictographs for carving stone memorials in old Egypt developed formal hieroglyphic writing, the key to which was afforded by the famous stone found at Rosetta by Napoleon's invaders. Thomas Young (1773-1829), the handsome and brilliant British physician-scientist, first attempted an analysis of the hieroglyphic text by comparing it with what he correctly assumed to be a translation on the same stone in demotic and Greek. However, it was J. F. Champollion (1790-1832) who successfully enough unraveled the mysteries of hieroglyphic to unloose the flood of Egyptologists 
who have followed. In his usual clear manner, F. Ll. Griffith has well reviewed the ancient Egyptian language and writing.

There were many specially trained scribes in old Egypt. Attached to the temples or to the households of major officials, they sat cross-legged day after day recording events or possessions. They compiled and copied stories, poems, songs, texts, recipes and formularies. The professional medical writings, both texts and formularies, are impressive.

Hieroglyphic was used for formal recording by carving on stone. When papyrus was developed, with brush-andink writing, a cursive script evolved which is known as hieratic. This was written from right to left, with red ink for the headings and black ink for the bulk of the material. From this two-toned system are derived the rubrics of our finely printed books.

Papyrus was made by interweaving split river-reeds (Cyperus papyrus), pounding the crude mats under water, and drying them to form coarse brownish sheets. After being written upon with a delicate brush, made from a frayed reed, they were glued together at the edges, to make a roll. Thanks to the everlasting dryness a surprising number of these papyri have survived from old Egypt. They have been most carefully studied, and the various analyses of them have given us a broad picture of the amazing scope and brilliance of ancient Egyptian culture.

An excellent account of the source, making, and use of papyrus is given by Sir Edward Maunde Thompson. Pliny describes its manufacture into sheets of various sizes approximating ordinary typewriting paper. An interest- 
ing picturization of the work of ancient Egyptian scribes has recently been made by W. C. Hayes and H. M. Herget. For proper preservation the present custom is for the scroll to be separated into its sheets, which are then hermetically sealed between glass plates so that they may be individually studied. 


\section{The Chief Egyptian Medical Papyri}

Ancient Egyptian medical practice may be quite satisfactorily reconstructed from an analysis of the available sources. These are mainly the eight papyri known as the Kahun, the Edwin Smith, the Ebers, the Hearst, the Erman, the London, the Berlin, and the Chester Beatty. A careful analysis of these documents has been undertaken by the famed Egyptologist, Hermann Grapow. They have also been well summarized by the great medical historian, Henry E. Sigerist.

Table 1

The Chief Egyptian Medical Papyri

\begin{tabular}{|c|c|c|c|}
\hline Name & Date & Location & References \\
\hline Kahun & 1900 B.C. & London & Griffith, 1898 \\
\hline Edwin Smith & 1600 B.C. & New York & Breasted, 1930 \\
\hline Ebers & 1550 B.C. & Leipzig & $\begin{array}{l}\text { Ebers, 1875; } \\
\text { Wreszinski, 1913; } \\
\text { Ebbell, } 1937\end{array}$ \\
\hline Hearst & 1550 B.C. & Berkeley & $\begin{array}{l}\text { Reisner, 1905; } \\
\text { Wreszinski, 1912; } \\
\text { Lutz, Larkey, } \\
\text { Leake, } 1939\end{array}$ \\
\hline Erman & 1550 B.C. & Berlin & Erman, 1901 \\
\hline London & 1350 B.C. & London & Wreszinski, 1912 \\
\hline Berlin & 1350 B.C. & Berlin & Wreszinski, 1909 \\
\hline Chester Beatty & 1200 B.C. & London & Jonckheere, 1947 \\
\hline
\end{tabular}

From the period of the Middle Kingdom, about 1900 B.C., have come remnants of a medical treatise dealing with diseases of women and animals. These were found 
at Kahun and have been published in transcript and translation by Griffth. Omitting the veterinary portion, the particular female diseases described are explained on the basis of uterine conditions or "wanderings." The descriptions indicate symptoms, what the physician should say, and then suggested treatment. This general organization of discussion for each particular condition is similar to that of the "cases" offered in the Edwin Smith and Ebers Papyri.

One might appropriately quote here one of the prescriptions in the Kahun Papyrus which was used by Doctor Clendening in his helpful Source Book of Medical History (Hoeber, New York, 1942): "Examination of a woman whose back aches, and the inside of her thighs are painful. Say to her, it is the falling of the womb. Do thus for her: ua grains, shasha fruit 5 ro, cow's milk $1 \mathrm{hnw}$, cook, let it cool, make it into a gruel, and drink for four mornings."

The third page of the fragment is not organized in the same manner as the first two. It contains a number of recipes for determining whether a woman is barren or fertile, and for promoting or preventing conception. Some of these prescriptions, dealing with matters of pregnancy, occur again in the Berlin Medical Papyrus.

Somewhere toward the beginning of the XVIII Dynasty, and the new empire, about 1600 B.C., the existing copy of the Edwin Smith Surgical Papyrus was written. It was acquired by the accomplished but too modest Egyptologist, Edwin Smith (1822-1906), in Luxor in 1862. On Smith's death, the document was presented by his daughter to the New York Historical Society, and has recently 
been transferred to the New York Academy of Medicine. In 1930 appeared the detailed study of the Smith Papyrus by the late Professor James H. Breasted (1865-1935). This is a work of overwhelming proportions and great importance, comprising a full-size facsimile, hieroglyphic transliteration, translation, commentary, analysis, and much enthusiasm. In this work, Breasted enjoyed the advantage of technical medical advice from his colleague, Doctor Arno B. Luckhardt, Professor of Physiology at the University of Chicago and widely known for his contributions to the history of medicine.

Table 2

Character of Chief Egyptian Medical Papyri

Name

Kahun, 1900

B.C.

Smith, 1600

B.C.

Ebers, 1550

B.C.

Hearst, 1550

B.C.

Erman, 1550

B.C.

London, 1350

B.C.

Berlin, 1350

B.C.

Beatty, 1200

B.C.
Condition

Fragmentary, 3

sheets

Unfinished; 17

columns; 4 on verso

Complete in 108

columns (num-

bered 110)

Incomplete;

18 columns

9 columns;

6 on verso

Fragmentary;

19 columns

21 columns;

3 on verso

Incomplete;

8 columns
Contents

Unorganized on women's diseases \& pregnancy

Well-organized surgical text;

48 typical cases; cosmetic recipes on verso

Medical text; hundreds of recipes classified by diseases; few. "cases"; anatomical monographs

Poorly organized practitioner's recipe book

Popular charms for childbirth and care of infants; 2 prescriptions

Recipe book with recitals

Recipes, recitals, signs of pregnancy

Formulary for anal diseases, one case report

The Edwin Smith Surgical Papyrus is an astonishing document. It comprises seventeen columns of hieratic writ- 
ing, with four and a half columns on the verso. A skillfully organized surgical text, it contains forty-eight typical "cases." The work was left unfinished by the scribe, in the middle of the forty-eighth case, which deals with an injury to the spine. There are a series of cosmetic recipes and "recitals" on the back of the document.

The case histories in the Edwin Smith Surgical Papyrus are organized in a logical manner, which in expanded form is customary even now. The material in each case is presented under a heading, written in red ink, followed by the examination to be made, the diagnosis to be offered as a result of the examination, an implied prognosis, and (if the prognosis is favorable) the treatment to be undertaken. One may think it peculiar that the diagnosis in many cases merely repeats the words used to describe the findings in the examination. In the absence of a technical terminology this might be expected if the diagnosis were thought not to be merely a label but rather an attempt at understanding. Often now a physician, having exhaustively examined a patient who comes complaining of a pain in the chest, may triumphantly announce a diagnosis of angina pectoris. So why blame the old Egyptians?

One might again illustrate the case histories of the Edwin Smith Surgical Papyrus by reference to one which, again, was quoted by Doctor Clendening. This is Case 11, dealing with a broken nose.

Instructions concerning a brcak in the column of the nose: If you examine a man having a break in the column of his nose, his nose being disfrgured, and a (depression) being in it, while the swelling that is on it protrudes, and he has discharged blood from both his nostrils, you may say concerning him: "One having a break in the column of his nosc. An ailment which I will treat." 
You should cleanse it for him with two plugs of linen. You should place two other plugs of linen saturated with grease in the inside of his two nostrils. You should put him at his mooring stakes until the swelling is drawn out. You should apply for him stiff rolls of linen by which his nose is held fast. You should treat him afterward with lint every day until he recovers. As for: "The column of his nose," it means the outer edge of his nose as far as its sides on the top of his nose being the inside of his nose in the middle of his two nostrils. As for: "His two nostrils," it means the two sides of his nose extending to his two cheeks as far as the back of his nose.

The various "cases" refer to injuries to the head, neck, and upper parts of the body, resulting from accident or fighting. One may classify the cases offered as follows: brain and skull, 1 to 10 ; nose, 11 to 14 ; face, 15 to 17 ; temporal bone, 18 to 22; ears, jaw, and chin, 23 to 27 ; neck and throat, 28 to 33; collar-bone, 34 and 35; upper arm, 36 to 38 ; chest and ribs, 39 to 46 ; shoulder, 47 ; and spinal column, 48.

The extraordinarily rational character of the presentation is well emphasized by Breasted. An interesting feature of the document is the fact that the scribe, writing it around 1600 B.C., was copying from a much older document, which may have dated from a period as early as 3000 B.C., to judge from the character of the glosses which the scribe introduced to explain archaic terms.

Breasted makes much of the remarkable scientific character of the surgical material in the Edwin Smith Papyrus. The effort is clearly an abstraction of typical situations culled from a wide practical experience. The organization of the material in "cases" dealing with injuries progressively considered from the top of the head downwards, suggests its compilation for teaching purposes. The 
document indeed may be the first scientific text preserved to us from antiquity.

The Ebers Medical Papyrus is a document of somewhat the same sort, dealing, however, with medical conditions rather than surgical. It was acquired by Georg Ebers (1837-1898) and was reproduced by him in sumptuous facsimile in 1875. A premature attempt at a translation was made by Joachim in 1890. An extended analysis was made by Walter Wreszinski in 1913, and B. Ebbell published an English translation in 1937.

The Ebers Medical Papyrus seems to be a complete document, in 108 hieratic columns. The scribe wrongly numbered them 110. The material in the Ebers Papyrus appears to have been brought together from a number of separate sources. It begins with three general "recitals". and then proceeds with many hundreds of recipes, classified rather loosely in accordance with the diseased states to be treated. It includes some "cases" in which the material is organized by title, examination, diagnosis, prognosis, and treatment. There are also some sections devoted to superficial anatomical description.

The contents of the Ebers Papyrus may be classified as follows, with reference to the columns: recitals, 1 and 2; compilation of remedies for internal diseases, 2 to 55 ; prescriptions for the eyes, 55 to 64; recipes for the skin, 64 to 76; recipes for diseases of the arms and legs, 76 to 85 ; a formulary for various conditions, 85 to 93; a formulary for female conditions and household matters, 93 to 98; two monographs on the heart and vessels, with glosses, 99 to 103; and at the end a section on treatment of surgical 
conditions, 103-110. There are some 829 prescriptions in the document, with little duplication.

The Ebers Medical Papyrus is a most imposing and important document. It deserves much more extensive study and annotation than it has so far received. Much still remains to be accomplished in identification of diseased conditions to which reference is made. There is also much remaining to be undertaken in the identification of the various drugs recommended. The Ebers Medical Papyrus is an intellectual effort of equal importance with the Edwin Smith Surgical Papyrus. Since it deals with conditions where the cause is often obscure, there is not quite the same clarity of definition or opinion as would be possible in a surgical writing, where the cause of the injury is usually obvious and clear-cut. Under these circumstances it is remarkable that there is not more indication of magic and supernaturalism in the text.

There is general agreement that the Kahun, Smith, and Ebers Papyri were designed to be texts for study and training. The Hearst Medical Papyrus, written during the great XVIII Dynasty, at about the same time as the Ebers Medical Papyrus, is a different sort of compilation. It is quite clearly a practicing physician's formulary. While there is evidence that there was a considerable degree of specialism in medical practice among the old Egyptians, there must have been general practice in the rural areas. It may well have been that some general practitioner from the country, coming into one of the large centers for some purpose or other, employed a scribe to collect for him a series of prescriptions relating to various diseased conditions in which he might have been interested. The organi- 
zation of the Hearst Medical Papyrus indicates that this may have been the situation.

With frayed beginning and end, the Hearst Medical Papyrus is incomplete, and exists in eighteen columns. It was first described in 1905 by George Reisner (1867-1942) to whom it was given when he led the Hearst Expedition to Egypt in 1899. It was transliterated and translated in part by Wreszinski in 1912. Containing a greater number of invocations and "recitals" than the Ebers Medical Papyrus, it has some 255 prescriptions for a variety of conditions. These are poorly organized, and in many places are repeated. Furthermore, many of the prescriptions occur in the Ebers Medical Papyrus as well as in the Berlin Medical Papyrus.

A medical papyrus dealing largely with infants and childbirth has been translated and edited by Erman. It is in the Berlin Museum (Papyrus 3027) and was titled Zaubersprüche für Mutter und Kind. This has nine columns on the recto and six on the verso. It includes a collection of popular recitations regarding diseases of infants, $n s w$ and $t m j t$. It also contains magical incantations regarding childbirth and the protection of infants. There are two prescriptions recommending simple drugs for an unknown disease of infancy. While this papyrus is not a professional medical writing, its discussion is justified because of the information it shows regarding the attitude of the people of the time about motherhood and infancy, and thus to contrast their superstitious attitude about disease with the direct empirical professional approaich indicated in the medical papyri designed as textbooks. The Erman 
document was apparently written at the end of the Hyksos Period around 1600 B.C.

A medical compilation containing both professional material and popular magic, is the London Medical Papyrus (British Museum 10059), written at the end of the XVIII Dynasty around 1350 B.C. This was annotated by Wreszinski in 1912. Many of the prescriptions were copied from an older document, as indicated by the lack of understanding on the part of the copying scribe. This papyrus is not in good condition. It contains nine columns on the recto and ten on the verso. With many recitals for use against various diseases, it also contains some sixty-one prescriptions. It concludes with prayers which have no connection with the context of the treatise.

More closely related to the Ebers and Hearst Medical Papyri is the Berlin Medical Papyrus (Berlin Museum 3039). This was annotated by Wreszinski in 1909. It is a poorly organized physician's formulary, similar to the Hearst Medical Papyrus. There are twenty-one columns, with three on the verso written by a different scribe. The material on the verso relates to tests used to tell whether or not a woman may have children. The Berlin Medical Papyrus contains some 200 recipes for various diseased conditions, and describes five typical cases of sickness. Many of the prescriptions are the same as, or similar to, those existing in the Ebers and Hearst Papyri.

The Berlin Medical Papyrus was probably written during the XIXth Dynasty, around 1300 B.C. Like the other medical papyri it probably was copied from parts of older documents. Interestingly, it contains a portion of the same treatise on blood vessels which occurs in the Ebers Papy- 
rus. This section closes with reference to "the scribe of sacred writing, the chief of wise physicians, Neterhotep, who made the book." This is one of the few references in ancient Egyptian literature to the name of a specific physician.

- Another interesting medical papyrus has recently been transliterated by the well-known English Egyptologist, Alan H. Gardiner. It was translated and annotated in 1947 by F. Jonckheere. This appears to have been written in the XXth Dynasty around 1200 B.C. It consists of eight columns with a frayed beginning and ending, and is part of a treatise dealing with recipes for diseases of the anus. It seems probable that there were anal specialists in ancient Egypt, and this would be a particular monograph for such practitioners. This papyrus was given by Chester Beatty to the British Museum (Papyrus 10686). It includes one case description. Most of its recipes are not to be found in other papyri.

The eight papyri which have been described comprise the direct evidence we possess of the professional skill of the old Egyptians in medical fields, as contrasted with popular beliefs and superstitions about disease. It is to be hoped that more medical papyri may be discovered and published, so that we may be in a more satisfactory position to judge the validity of the present tendency of opinion regarding the character of ancient Egyptian medicine.

The most thorough analysis of the seven professional Egyptian medical papyri (omitting the Erman document) has been made by the famed German Egyptologist, $\mathrm{H}$. Grapow. From the evidence available, it would appear that (1) the ancient Egyptian physicians were relatively 
keen and accurate observers; (2) they possessed a systematic method of examination; (3) they were exploring the principles of diagnosis; (4) they had an idea of the significance of prognosis, and thus were aware of the natural course of untreated disease, and (5) they had accumulated a large body of tested agents and methods for the treatment and management of sickness. It is surprising that there is not more evidence of supernaturalism in the medical papyri. The various "recitals" may reasonably be interpreted as "prayers" for skill and guidance, not only in regard to handling the patient but also in respect to the measurement of drugs. Taken as a whole the evidence from the papyri indicates a relatively high standard of medical practice in old Egypt. 


\section{Old Egyptian Weights and Measures}

ne of the most satisfactory achievements of the great English Egyptologist, F. Ll. Griffith (1862-1934), was to clarify for modern understanding the complicated and confusing symbolism and notation for old Egyptian weights and measures. This was done by extensive correlation between the mathematical and medical hieratic papyri and various hieroglyphic inscriptions. Griffith's findings, taken with William Ridgeway's brilliant historical analysis (1892) of the origin of currency and weight standards, would suggest that measurement developed gradually and empirically, with simple parts of the human body as readily available references for comparison, or later for conventionalizing into standards. With the variations thus naturally occurring, ample excuse would exist for the protracted bargaining in commerce and trade which remains so characteristic a feature of Mediterranean culture to this day. The practical problem is to reach an agreement on standards of measuring. Historically the matter is so confusing because the standards vary so greatly in different places and times.

For practical purposes of measuring relatively short distances, the digit or palm or span of the hand was generally convenient. For laying out construction or furniture, it was probably more easy to employ the cubit (elbow to knuckles), since a string could be held between the fingers and wrapped from elbow to knuckles to give integral multiples. For estimating land distances or areas, one could most readily measure by foot or by pace. Any rela- 
tionship between these elemental units must have developed arbitrarily, on the basis of integral multiples of the smallest unit.

\section{Table 3}

\section{Egyptian Doubling System for Length}

Primitively based on hand \& arm referents

$\begin{array}{lll}2 \text { digits } & \text { is one-half hand } & \text { ( } 2 \text { inches) } \\ 2 \text { half-hands } & \text { is one hand } & \text { ( } 4 \text { inches) } \\ 2 \text { hands } & \text { is one span } & \text { ( } 8 \text { inches) } \\ 2 \text { spans } & \begin{array}{l}\text { is one cubit } \\ \text { (elbow to knuckles) }\end{array} & \text { (16 inches) } \\ 2 \text { cubits } & \text { is one yard (arm) } & \text { (32 inches) } \\ 2 \text { yards } & \text { is one fathom } & \text { (spread of } 64 \text { inches) }\end{array}$

The above for furniture \& buildings. For distances, the foot \& pace were standard.

For capacity estimation it seems again that convenient reference was made to human factors, such as a mouthful (table-spoonful), handful or cupful (two-handsful), or sack- (hide-) ful (for easy carriage).

The idea of weighing or of measuring differences in weights must have arisen as a result of comparisons of volume. In equivalent volumes some things would be observed to be lighter than others, and some things heavier. This matter would naturally become important in the trade of rare and precious materials like gold dust or incense. Arbitrary weights of common but valued objects such as gold rings or anklets seem to have early been used as weight standards. By rough equivalence to the amount of work involved in obtaining them, arbitrary standards for currency seem to have evolved. Ridgeway shows how 
individual wealth was primitively estimated by cattle rather than by land, which was held in common. As weighing of gold dust developed, the unit of gold value was related to that of a cow. Early weights are often found in the form of a cow-head.

Surviving suspension balances with pans and weights from predynastic times indicate the great antiquity of relatively accurate methods of weighing by the old Egyptians. The sensitivity of small balances for weighing precious things like gold or frankincense would probably have suggested some common natural object of relatively uniform and constant size and weight for use as a standard for comparison. Grains of wheat are remarkably uniform in size and weight, and seem early to have been used for such purposes. These "grains" (0.064 gm.) have persisted to this day as weight standards. Barley grains are slightly smaller $(0.048 \mathrm{gm}$.) and weigh less than wheat grains, and seem to have been, according to Peet, the origin of troy weights, by which gold and precious drugs were weighed.

It is interesting to note that old Egyptian drug measurement seems usually to have been made by capacity estimation, even for such rare and valuable drugs as frankincense and myrrh. In the Hearst Medical Papyrus, for example, although one of the prayers refers to weighing by $d b n$, none of the prescriptions seem to call for drug amounts by weight. All apparently specify volume amounts, usually fractions or multiples of the ro (mouthful) for the drugs themselves, and fractions or multiples of the hnw (jugful) for vehicles.

It is rather astonishing that none of the great Egyptolo- 
gists have been impressed by the practical aspect of the spoonful. Griffith, Petrie, Wreszinski, and Ebell have thoroughly studied old Egyptian drug measurement. None of them seem to have recognized the relation of the ro

\section{Table 4}

\section{Old Egyptian Volume Doubling System}

1 ro is a mouthful (tablespoonful)

$2 r o$ is a handful (Aluid ounce, jiggers)

4 ro is two handfuls (jack)

$8 \mathrm{ro}$ is four handfuls (gill)

16 ro is a cupful (two hands cuppedful)

32 ro is a jugful (pint, Hnw)

64 ro is a pitcherful (quart)
or $14-15 \mathrm{mls}$.
or $28-30 \mathrm{mls}$.
or $56-60 \mathrm{mls}$.
or $112-120 \mathrm{mls}$.
or $224-240 \mathrm{mls}$.
or $448-480 \mathrm{mls}$.
or $896-960 \mathrm{mls}$.

10 Hnw (320 ro) was 1 Hk.t (amphoraful, or 4.5-4.8 liters)

The remarkable persistence of this volume-doubling system is apparent in old English measures which go on: two quarts is a pottle; two pottles is a gallon; two gallons is a peck; two pecks is a pail; two pails is a bushel; two bushels is a strike; two strikes is a coomb; two combs is a barrel; two barrels is a hogshead; two hogsheads is a pipe; and two pipes is a tun.

(mouthful) to the tablespoonful, or to have appreciated the convenience of the tablespoon as a measuring utensil for drugs. In his comprehensive analysis of objects of daily use in old Egypt, Sir Flinders Petrie describes only one spoon from the XIIth Dynasty. He notes bronze unguent spoons from Roman times.

In the great Egyptian collections of the Metropolitan Museum of Art in New York City there are four interesting tablespoons obviously for ordinary household use. Three are early dynasty spoons of bone, with cylindrical bone handles from 7 to 9 inches long, each with a tiny 
perforated hole near the flanged tip of the handle. The bowls of these spoons are oval, holding about 14 cubic centimeters, or a mouthful. The bowls are attached to the handles in a manner unusual to our current concept of a spoon, for the long axis of the oval bowl is at right angles to the spoon handle. From the XVIIIth Dynasty, however, is displayed a wooden spoon of the currently conventional form, about 12 inches long, with a pointed oval bowl, the short axis of which is at right angles to the handle. This bowl also holds about 14 cubic centimeters, or a mouthful. The Metropolitan Museum also shows duck-billed scoop-spoons which were probably used for transferring grain from one container to another, and

\section{Table 5}

Old Egyptian Tablespoons in American Museums

\begin{tabular}{|c|c|c|c|}
\hline $\begin{array}{l}\text { Museum and } \\
\text { Identification }\end{array}$ & $\begin{array}{l}\text { Overall Size } \\
\text { and Material }\end{array}$ & $\begin{array}{l}\text { Bowl Size } \\
\text { and Shape }\end{array}$ & $\begin{array}{l}\text { Probable } \\
\text { Period }\end{array}$ \\
\hline $\begin{array}{c}\text { Metropolitan } \\
12.187 .30\end{array}$ & $\begin{array}{l}9 \text { inches } \\
\text { bone }\end{array}$ & $\begin{array}{l}12-15 \mathrm{cc} . \\
\text { transverse oval }\end{array}$ & $\begin{array}{l}\text { 1st Dyn. } \\
3400 \text { B.C. } \\
\text { Tarkhan }\end{array}$ \\
\hline $\begin{array}{c}\text { Metropolitan } \\
09.182 .19\end{array}$ & $\begin{array}{l}12 \text { inches } \\
\text { bone }\end{array}$ & $\begin{array}{l}12-15 \mathrm{cc} . \\
\text { transverse oval }\end{array}$ & $\begin{array}{l}\text { Early Dyn. } \\
\text { El Mahasuch }\end{array}$ \\
\hline $\begin{array}{l}\text { Metropolitan } \\
23.2 .12\end{array}$ & $\begin{array}{l}7 \text { inches } \\
\text { bone }\end{array}$ & $\begin{array}{l}12-14 \mathrm{cc} \\
\text { transverse oval }\end{array}$ & Early Dyn. \\
\hline $\begin{array}{l}\text { Metropolitan } \\
26.2 .34\end{array}$ & $\begin{array}{l}12 \text { inches } \\
\text { wood }\end{array}$ & $\begin{array}{c}14-15 \mathrm{cc} . \\
\text { conventional } \\
\text { spoon oval }\end{array}$ & XVIII Dyn. \\
\hline $\begin{array}{l}\text { National; } \\
\text { Gulbenkian } \\
\text { Egyptian No. } 7\end{array}$ & $\begin{array}{l}8 \text { inches } \\
\text { carved ivory }\end{array}$ & $\begin{array}{c}12-15 \mathrm{cc} \\
\text { indented oval }\end{array}$ & XVIII Dyn. \\
\hline
\end{tabular}

spoon-shaped ointment or cosmetic receptacles shaped like a little boat held by a prone smiling girl.

A beautifully carved ivory tablespoon, flat-bowled but 
holding about 12 to 15 cubic centimeters (a mouthful), is in the Gulbenkian Collection of the National Gallery of Art, Washington (No. 7). It is about 8 inches long. Although described as a toilet spoon, it more closely resembles a tablespoon, elaborately decorated for the use of some prominent person.

Much discussion has occurred regarding the frequent specification in the great Egyptian medical papyri of the XVIIIth Dynasty of 5 ro, the hieratic symbol for which was a single vertical stroke, probably corrupted from a simple cross. Griffith makes much of this as the cubic quarter (1/64) of the $h k . t$, the common grain measure (jar) of about half a peck (4.5 liters). He emphasizes the old Egyptian system of calculating by doubling or halving in relation to the decimal method also used for multiplying or dividing. The $h n w$ (jugful, 1 pint, 0.45 liter) was $1 / 10$ of the $h k . t$. He then concludes that for volume measurement the ro was merely a notation for the least common denominator (1/320), the "part" par excellence, of the two systems, and not an actual volume at all.

This does not logically follow, nor is it in accord with evidence. The hieroglyph for the ro was the shape of the mouth as simply or primitively drawn, a flat arch above meeting its reverse below. The quantity involved, as anyone can determine by trial, is about a tablespoonful (14 to $15 \mathrm{cc}$; $1 / 2$ fluid ounce). As a definite quantity this would fit all the requirements for the smallest unit in the hnw$h k . t$ system as indicated in the conversion table of the Rhind Mathematical Papyrus of the same period (XVIIIth Dynasty). This table, as so well discussed by Thomas Eric Peet (1882-1934), shows the relations between volumes 
obtained by halving, measured by reference to the $h n w$ or to the $h k . t$, with $10 \mathrm{hnw}$ equaling $1 \mathrm{hk}$.t.

It will be noted from the Rhind conversion table that $1 / 64 h k . t$ was equal to 5 ro. The hieratic symbol for this amount was a vertical stroke, which was probably cor-

\section{Table 6}

Conversion Table "hnw" To "hk.t"

(From Rhind Mathematical Papyrus, plate W, in account by T. Eric Peet, University of Liverpool Press, 1923)

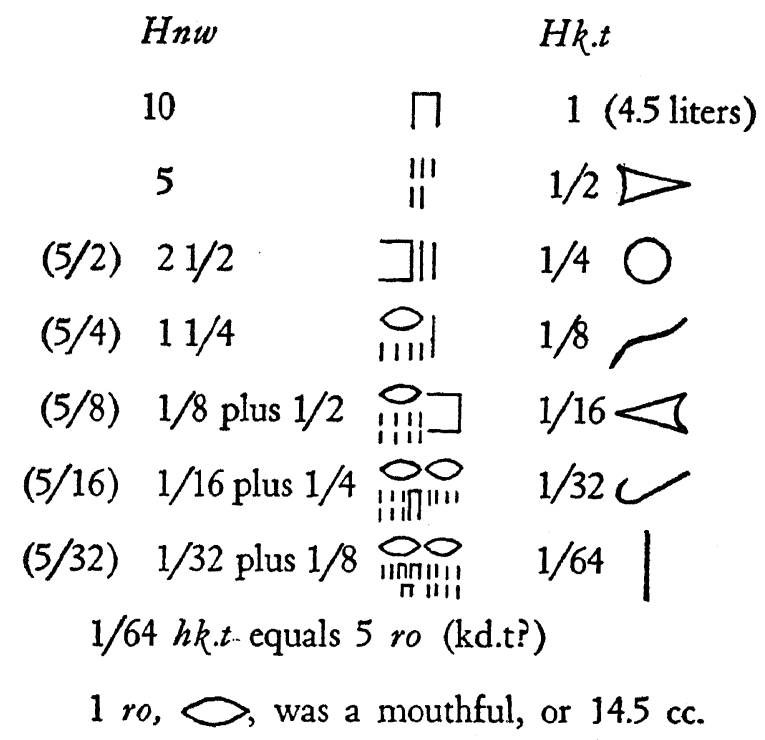

rupted from an earlier cross. There may, however, have been some differentiation. There is the possibility that the hieratic symbol might also have referred to a measure of weight. This might have been the $k d . t$, which later became in Coptic kiti, and retained its approximate value of 140 
to 150 grains, or $91 / 2$ grams. This corresponded generally to the weight of a gold finger ring. A drachm apparently developed as $1 / 2 k d . t$. Ten $k d$.t was one $d b n$ or approximately 95 grams, the ordinary weight of a gold anklet. According to the Rhind Mathematical Papyrus (No. 41) $5 d b n$ of water equaled one $h n w$. Here we may have the first indication of groping toward the idea of specific gravity.

It is not clear that any of the prescriptions in the Egyptian medical papyri call for drug amounts in weight. This matter is under study now, on the assumption that the hieratic symbol of a small cross indicates a $k d . t$ as weight, while the vertical stroke may be the symbol for 5 ro in volume, as 1/64 hk.t. It may also be possible that the vertical stroke signified either 1 ro in volume $(15 \mathrm{mls}$.) or one $k d . t$ in weight (9.5 gms.), depending on the context or the drug to be measured. Actual experiments in compounding some of the prescriptions offer some evidence in support of this hypothesis.

An interesting feature of drug measurement is the confusion existing over some of the "recitals" for the measuring utensils as given in Hearst 212 and 213. Doctor Henry Sigerist suggests that these "recitals" may have had magic implications. When these "recitals" are first examined they may seem irrational, particularly in the reference to the god Horus measuring his eye.

Hearst 212 may be translated as follows: "The recital for the measuring utensil on taking it in order to measure a prescription: 'As for this measuring utensil, this prescription shall be measured with it. It is the measuring utensil with which Horus measured his eye (lotion). It is 
tested; there is found (through it) life, well-being and health. This prescription is measured with this measuring utensil in order to remove therewith every sickness which is in this body." "

Horus was the good beneficent son of Isis, whose eye was gouged out by his wicked brother, Seth. Isis, the good mother, put the eye together again for Horus. Much subsequent symbolism developed about the "Horus Eye." The significance of the symbolism is given in the Rhind Mathematical Papyrus (sheet W), in the important conversion table for the hnw system to the hk.t system. Here the hieratic symbols are given for the various parts of the $h k$.t.

\section{Table 7}

\section{Old Egyptian "Horus Eye" Symbol for Measurement}

Horus, son of Isis, beneficent deity, had his eye pulled out by his wicked brother. It was put back by Isis and healed. The old hk.t system of volume measurement was converted to the new hnw system by the Horus Eyc symbolism (Rhind Mathematical Papyrus, Plate W). Georg Möller gave the clue to the symbolism (Ztschr. Aegypt. Spr. 48:99-106, 1911).
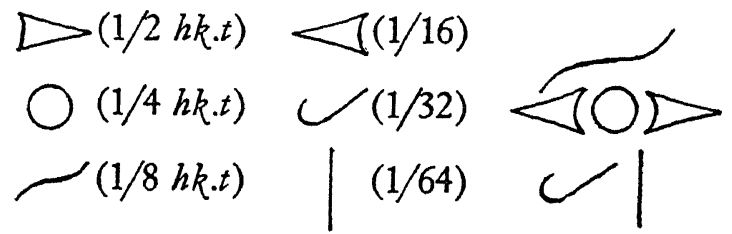

Georg Möller gave the clue to the symbolism, and suggested that the reference to the "Horus Eye" was a device whereby the scribe could remember the various symbols involved. With this interpretation, the "recitals" referring to the "Horus Eye" can be interpreted as reminders of drug quantities for the memory of the physician, or of the pharmacist compounding the prescriptions. 
It is suggested that the old $h k . t$ system of dry measure in old Egypt was supplanted in part during the Hyksos invasion by a decimal system introduced from the east and based on the $h n w$. It was necessary then for a conversion table to be established, so that measurements might satisfactorily proceed in either system. There exist today in Egypt many confusing systems of weights and measures. Commercial factors are certainly involved. The shrewd trader can always know where to buy long quantities and to sell short. This factor has probably been one of the most effective deterrents to the establishment of uniform systems of weights and measures. Under all the circumstances involved it is remarkable that the old Egyptians had as effective a system of weights and measures as was the case. Considerable uniformity is shown in the surviving measuring utensils from the ancient period, as reported by Sir Flinders Petrie. There is evidence of a chronological diminution, as one might expect under pressure of commerce and inflation. 


\section{Drug Measurement in the Old Egyptian Medical Papyri}

$A_{\text {remarkable feature of the old Egyptian medical }}$ papyri of the XVIIIth Dynasty (the brilliant period of Egyptian culture about 1550 B.C.) is the care indicated in so many of the prescriptions in giving directions for measuring the drugs recommended. In the Hearst Medical Papyrus, a practicing physician's formulary, there are some 262 headings. When allowance is made for incomplete prescriptions and recitals, one may find that of the 65 prescriptions stipulated for administration by mouth, 53 (81 per cent) are quantitative. On the other hand, of the 190 indicated for external application, only 68 (35 per cent) specify amounts of the drugs to be used. Of the latter, many (such as H 217-224; XIV:13-XV:3) are for casts for broken bones and for immobilization bandages with ointments for injured joints and muscles. Here experience may have shown the necessity for definite proportions of the different sticky ingredients in order to achieve the effects desired. In the great Ebers Medical Papyrus, probably compiled as a text for teaching purposes, 86 per cent of the prescriptions for oral use are quantitated, while 62 per cent of those for external use include measured drug amounts.

A group of prescriptions for the same purpose (as $\mathrm{H}$ 206-210; XIII:12-XIII:16, for $n s j . t$ ) sometimes opens with several in which drug quantities are indicated, to be followed by one or more in which no amounts are specified. On the assumption that quantitation is a refinement 
gained by experience, is this evidence that the scribe selected prescriptions from various sources, with perhaps the more recent quantified ones chosen first, with some

\section{Table 8}

Quantitative Aspects of Medical Papyri

Internal Administration

$\begin{array}{lrcrc}\text { Papyrus } & \text { Quantitated } & \text { Non } & \text { Quantitated } & \text { Non } \\ \text { Ebers } & 294(86 \%) & 46(14 \%) & 305(62 \%) & 184(38 \%) \\ \text { Hearst } & 53(81 \%) & 12(19 \%) & 68(35 \%) & 122(65 \%) \\ \text { Berlin } & 68(68 \%) & 32(32 \%) & 12(12 \%) & 88(88 \%)\end{array}$

of the older more traditional ones added secondarily? Or may it indicate merely that the omitted amounts are to be assumed to be the same as in those prescriptions at the beginning of the group?

The quantitative aspects of the medical papyri raise questions of theoretical interest in the history of pharmacology: (1) Did the old Egyptian physicians recognize that drugs given by mouth have a more general systemic effect than those applied to the skin, and thus justify more care in preparation and administration? (2) Did they appreciate the fact that intensity of drug action in general varies directly with the quantity of the drug given? (3) Did they understand that precautions are wise in preparing and administering a potent drug so as to avoid possible toxic effects from too large a dose?

To these questions categorical answers cannot be given, but in general one would have a tendency from the evidence available to answer affirmatively. It seems that the old Egyptian physicians, like their compatriots generally, 
were reasonable men, practically inclined, and profiting from experience. On the other hand, they indicated no inclination toward abstract thinking. They developed no systematic theory of health and disease, and no accompanying arbitrary principle of treatment. They had no "scientific" system of measures and weights, with systematic relations established a priori by agreement. They were empiricists, and their medical precepts and the amounts of the drugs they prescribed, as indicated by what has survived, were derived from their experience. They dealt with the specific conditions of their patients, and made little attempt to generalize further than offering recommendations for handling what must have been frequently occurring situations. They measured their drugs by convenient, practical, and empirically developed capacity utensils.

Consequently, they seem to have realized that drugs taken by mouth are apt to have more general effects than those applied locally to the skin, but they certainly did not generalize from this to any recognition of factors involved in the absorption and distribution of drugs. Similarly, they seem to have fully appreciated the rather obvious fact that there is some relation between dose and effect, but they did not make any effort to investigate this relationship or to deal with it abstractly and systematically. Again, they seem to have understood that some drugs are more potent than others, on the basis of equal amounts, and that care is necessary to avoid harmful effects from overdosage. It is doubtful that they had as clear an abstract appreciation of the matter as thus expressed. They apparently realized, however, that some drugs are best given in small 
amounts, while others may be tolerated satisfactorily in much larger quantities. It is significant that in their surviving medical writings there are no recommendations for the unwise use of any of the poisonous drugs described by Lucas as occurring naturally in Egypt.

Recommendations for drug measurement seem to parallel the rise and decline of cultural achievement in the broad sweep of old Egyptian history. The earliest of the extant medical writings is the Kahun Gynecological Papyrus of the XIIth Dynasty, around 1850 B.C. Of its 32 prescriptions, 5 ( 15 per cent) are quantitated. It is usually agreed that the most brilliant era of old Egypt was the XVIIIth Dynasty, the "New Kingdom" (1590-1320 B.C.), founded by A'h-mose after the expulsion of the Hyksos, when art and commerce flourished, when hieroglyphic inscription was standardized, when exploring expeditions were promoted, when monotheism was attempted, and

\section{Table 9}

Quantitative Prescriptions in Egyptian Medical Papyri

Papyrus

Kahun, 1900 B.C.

Smith, 1600 B.C.

Ebers, 1550 B.C.

Hearst, 1550 B.C.

London, 1350 B.C.

Berlin, 1350 B.C.
Quantitated Recipes

5 of 32

4 of 6

599 of 829

121 of 255

0 of 20

80 of 200
Per cent

66

72

47

40

when the land was at peace. The most skillfully organized and intellectually sound medical document of old Egypt is the Smith Surgical Papyrus of the XVIIIth Dynasty, 
copied, however, from an older original. Six prescriptions, cosmetic it is true, appear with eight recitals on the back of this scroll. Four of these prescriptions are quantified. The greatest medical writing of old Egypt, the Ebers Papyrus, a teaching text of the XVIIIth Dynasty, quantitates 599 of its 829 prescriptions ( 72 per cent). A practicing physician's recipe-book, the Hearst Papyrus of the same period as the Ebers, gives drug amounts in 121 of its 255 prescriptions (47 per cent), the bulk of its non-quantitative formulae being for external application. The Berlin Medical Papyrus of the XIXth Dynasty, probably written during the great reign of Rameses II (1298-1232 B.C.), quantifies 80 of its 200 prescriptions (40 per cent). However, in the London Papyrus of perhaps a slightly later date, with the bulk of the document consisting of spells and recitals, twenty prescriptions occur of which none give the amounts of the drugs to be used. On the other hand, the persistence of the tradition of quantification for drugs may be illustrated by the London Demotic Papyrus of the third century A.D., in which, in the midst of divinations, spells, and erotica, 46 prescriptions appear, of which 9 give the amounts of the drugs to be used (20 per cent).

The quantitative aspects of drugs are important in the development of current pharmacology. As significant generalizations, they are only now beginning to be studied and critically appreciated. Indeed, the first important theory for estimation of drug toxicity was developed only in 1927 by J. W. Trevan. The old Egyptian medicos may be pardoned for not having had the intellectual foresight to tackle this problem. For all the vaunted ability of the Greeks and their successors in Western cultures for ab- 
stract thinking, here is a matter of considerable practical importance which had to wait until recent times for an effective approach.

Part of the delay was due to the lack of adequate standards for drugs. This is a matter independent of adequate standards of quantitative measurement of volume or mass. A similar psychological factor, however, is involved. This is the matter of agreement. The essential problem in standardization is obtaining agreement on a standard of reference. It may be possible that trade and commercial angles inhibited for many centuries the approach to agreement on standards of reference for weights and measures, as for drugs. 


\section{Ancient Egyptian Therapeutics*}

Trescis

herapeutic principles are usually based on etiological considerations. The old Egyptians, like most primitive people, had clear and reasonably sound methods of handling direct external physical disabilities, such as fractures and injuries resulting from falls, or from such obvious causes as blows. About these matters there was apparently no uncertainty, no speculation regarding appropriate methods, no "magic," no irrational nor superstitious procedure. Primitive surgery and obstetrics seem quite generally to be of this character. On the other hand, internal disorders, particularly what we now call infectious diseases, have no obvious etiology. Their onset is usually insidious and not readily to be correlated with any specific circumstance. Under these conditions it is not surprising that speculation and fear should inspire conviction of supernatural causes, with resulting and logical use of supernatural and magical methods of treatment. A demoniacal etiology for disease requires treatment directed toward expelling the demon or appeasing it. Thus magical procedures are a natural and logical feature of that portion of primitive medicine concerned with internal diseases.

In the light of these considerations, one would expect the Edwin Smith Papyrus, dealing with surgical conditions, to be a sensibly designed document, as indeed it is. But one might be justified in not expecting it to be or-

* This section is modified from an article with the same title which appeared in Ciba Symposia, January, 1940, I, pp. 311-322. 
ganized along what are considered "modern" case-history lines, that is with case-history headings, physical findings, diagnosis, treatment, and prognosis. As Breasted points out, there is further cause for astonishment at the intellectual honesty of the ancient Egyptian surgical teachers in recommending no treatment where the prognosis is poor.

On the other hand, since the medical papyri deal chiefly with internal diseases, one might expect, with an assumed demoniacal etiology, to find an irrational hodgepodge of magical and demoniacal therapy. But this is not the case; nor is demoniacal etiology suggested, except so rarely as to be startling by its implied presence. On the contrary, the various prescriptions recommended seem to be quite rational and natural applications to the alleviation of symptom complexes of empirical knowledge of the general physiological properties of plant, animal, and mineral materials. This lore probably accumulated from observations made in the search for foods or by accidental contact with the skin.

Doctor Owsei Temkin has summarized various views on these matters, indicating the gradual tendency to support the empirical rationality of the chief Egyptian medical texts. This is in accord with the position of Hermann Ranke and also of Hermann Grapow. Grapow emphasizes the differences in the medical papyri depending upon whether they are to be used as textbooks, or merely as collections of recipes for practicing physicians. In the textbooks, the diagnoses are coherently expressed in sentence form. In the formularies the prescriptions employ loosely connected words and concepts. Grapow concludes that ancient Egyptian medicine reached its full develop- 
ment during the XVIIIth Dynasty, and from then on tended to degenerate. This degeneration may have resulted from slavish copying, without realization of the background of observational material upon which the ancient texts may well have been based.

In considering the old Egyptian medical texts, one cannot help being impressed by the fact that many of the words rendered into English by various scholars are derived from German translations. These frequently carry implications which are contrary to what the Egyptian script permits. For example, it is frequently stated by medical historians that the Ebers, Berlin, and Hearst Papyri contain a number of "incantations." In many instances these particular sections are headed by the hieratic character which is transliterated as $r$. This Egyptian word is ordinarily translated as "incantation." However, it is doubtful if it had such meaning. The hieroglyph for $r^{\prime}$ indicates that it is derived from a symbol for "mouth" ( $r o$ ), and it literally means "what is said by the mouth." Thus, the word $r$ is most appropriately translated by "recital," "saying," or some similar word. It does not carry at all the implication of magic ritual which is associated with the word "incantation."

It has been a difficult problem for scholars accurately to identify all of the many plant, mineral, and animal materials recommended for medicinal purposes in the Egyptian papyri. In many cases, identification has been made possible from later Coptic derivations of Egyptian words, and often from "determinatives" which indicate whether or not the material is granular in form, gummy in character, or a liquid. These determinatives may also 
show whether or not the material is a tree, root, bud, leaf, or other part of plants.

Often the uses to which the material is put has aided in identification. Similarly, the names given to different diseases often suggest appropriate translations, with which, however, great caution must be exercised to avoid jumping at conclusions. Ebbell has made many interesting proposals, some of which however may be disputed. An example occurs in the Hearst prescriptions 206-210 and the related Ebers prescriptions 751-754. These deal with nsj.t. This is translated by Ebbell as "epilepsy." Ebers 751 is headed "to expel nsj.t in the eyes." Unless this refers to nystagmus, it is difficult to understand what would be meant by "epilepsy in the eyes," if it were translated according to Ebbell. However, nsj.t is derived from sources which refer to "heat," "burning," and implies "to burn." It would seem more appropriate therefore to translate the word as "fever" or "burning." Such a translation would make these prescriptions understandable, both from the disease to which reference was probably made, as well as to the character of the ingredients of the prescriptions. These are such as would be expected to have been found to be more appropriate for the relief of fever than for the relief of epilepsy.

Another interesting illustration of confusion that may be caused by difficulties of translation occurs in the Hearst prescriptions 21-23. These refer to the treatment of bites. The translator usually gives the headings as "prescription for a bite by men," although sometimes the genitive is used. In either case, it is suggested that the prescription is recommended for the treatment of a bite made by men. 
However, there is no distinction in the Egyptian between the genitive, dative, or ablative case. It is quite as satisfactory from the linguistic standpoint, and certainly much more rational and understandable medically, to translate the heading as "a prescription for a bite on men." With this latter interpretation in mind, one might readily appreciate the rationality of the prescription from the standpoint of treating insect or other similar bites, which must have been as frequent in ancient Egypt as they are today. The remedies proposed are such as would be quite useful in soothing the irritation of insect bites. They would not, however, be appropriate for lacerated wounds made by bites inflicted by human beings on one another. Anyway, men rarely bite one another.

It is remarkable that the ancient Egyptian physicians discriminated between such closely related plant remedies as garlic and leek. The Egyptian symbol for "leek" is transliterated as $i k . t$. On the other hand, the Egyptian symbol translaterated as $h d w$ implies, from the determinative, an aromatic, white-colored plant material. This appears, from the further root determinative, to be a plant such as "garlic." It is translated, however, by Ebbell as "styrax," a resinous gum. This is highly improbable, since long ago Egyptologists identified nnib as "styrax," from its later Coptic derivative.

Thus it is clear that there are enormous difficulties in translation which must be surmounted before a satisfactory interpretation can be made of the various diseased conditions and remedies mentioned in ancient Egyptian medical texts. Agreement must be reached on the most probable meaning of the various symbols involved. 
The therapeutic procedures recommended in the Egyptian medical papyri appear on the whole to be relatively simple. They seem to favor natural restorative processes involving as little injury to the patient as possible. No significantly poisonous materials are recommended. The procedures thus appear to be in the spirit of what is ordinarily called "Hippocratic Medicine." Such are, for example, the surgical procedures in the removal of dead tissue, the applications of poultices or dressings, such as "fresh meat" to lacerated wounds, the immobilization of injured parts, and the preparation and application of splints.

In the Hearst Medical Papyrus occurs an interesting group of prescriptions $(10-14 ; 217-225)$ which superficially appear to be quite irrational for the purpose recommended. These are proposed for "the mending of broken bones." The ingredients suggested are meal or flour from beans, barley, or other similar plant materials, with honey, cream, or other thick liquid ingredients. In each case there is a glutinous material incorporated in a relatively thick liquid, and in each case such a preparation is to be applied with a bandage. As suggested by Doctor J. B. deC. M. Saunders, such an application, upon drying, would probably have resulted in a sort of cast. In fact, similar flour and water-paste casts were recommended surgically for broken bones as late as in the middle of the 19th century, before plaster-of-Paris casts were introduced.

Abrasions, lacerations, or inflamed areas on the skin seem to have been treated by the application of soothing mucilaginous preparations made from gummy plant materials such as frankincense and acacia, which might have 
at the same time a mild antiseptic action. A large number of bland, mild alkaline and mucilaginous materials seem to have been recommended for oral administration for the relief of "pain in the left side" and other similar conditions-a description which suggests gastric hyperacidity or peptic ulcer.

For the purpose of expelling various "accumulations" considered to be harmful to the body, numerous plant, mineral, and liquid materials having a diuretic or purgative action were proposed. Failure to identify accurately a large number of diseased conditions, some of which are indicated by specific names, makes it difficult to assess the rationality of the medical agents advised.

In general, it is reasonable to say that ancient Egyptian therapy seems to have been empirically rational. This was probably due chiefly to the fact that there was apparently no speculation regarding the etiology of the diseased conditions. Symptoms seem to have been treated as they appeared. There is evidence that some diseased conditions were considered to be acute, whereas others were thought to be more chronic. In the latter case, continuous treatment seems to have been implied by the direction for the remedy "to be given for four days." This may have been simply a conventional statement to indicate repeated administration. There seems to have been rationally applied to the relief of appropriate symptoms such observations on the general physiological properties of various plant, animal, and mineral materials, as might have been noted in the search for foods, or as a result of accidental contact with the skin.

It is interesting in connection with the Egyptian medi- 
cal papyri to note some of the factors which may have contributed to the rise of polypharmacy. In many instances, prescriptions for certain conditions are simple. However, a number of single ingredients may be recommended for the same condition as separate and individual prescriptions. There is evidence in some cases that the scribe or teacher simply combined a number of these in one prescription, since no indications appear regarding the relative merits of the single ingredients. Thus, Ebers prescription 660 contains all the ingredients in the same order and for the same purpose as they appear in divided state in the two Hearst prescriptions 117 and 118.

The prescriptions recommended in the Ebers and Hearst Papyri include both those which specify accurately the quantities of drugs and those which simply call for certain ingredients without specifying the amounts. In some instances there is evidence of recommendations of considerable care in accurate measurement, even to relatively small amounts, for certain ingredients. Usually these ingredients are such as might be expensive, as frankincense, or which might be toxic, such as certain mineral materials. Some prescriptions contain considerable detail regarding the method of compounding and preparation. For example, some are required to be concentrated to a particular amount, whereas others are required to be prepared in certain ways. These details indicate a marked degree of skill in what has later come to be known as "pharmacy."

Identified plant remedies occurring in the old Egyptian medical papyri include acacia, anise, barley, cassia, castorbean, coriander, cucumber, cumin, date, fennel, fig, fig- 
mulberry, garlic, gourd, juniper, leek, lettuce, lotus, peas, poppy seeds, saffron, sunflower, styrax, terebinth, wheat, willow buds, white thistle, and wormwood. There still remain some forty to fifty unidentified plant remedies. These materials are known to be plants by virtue of the determinative associated with the hieratic script. The identity of many of these agents is under discussion; some tentative identifications comprise thyme, myrtle, hyoscyamus, mustard, and cinnamon.

Included in the old Egyptian medical writings are references to such mineral remedies as alum, copper, feldspar, iron oxide, limestone, red ochre, sodium carbonate, sodium bicarbonate, salt, stibnite, sulphur, and possibly arsenical compounds. These remedies are usually recommended for mild astringent or antiseptic action in connection with application to the skin or to such conditions as boils, felons, and burns. Those mineral materials which possess strong color were also recommended for cosmetic use.

Among resinous materials recommended as remedies occur such mild antiseptic agents as frankincense, myrrh, styrax, turpentine, and such plant mucilaginous materials as acacia gum.

A considerable number of beverages are included in the prescriptions, and appropriately enough, usually as vehicles. Beer, milk, wine, and honey are the common vehicles for most of the prescriptions containing more than one ingredient. Honey is recommended as the excipient, or binding agent, for such combinations as were to be rolled into pill form by the fingers.

While a large number of different types of drugs from 
animal sources are recommended in the medical papyri, their use seems less extensive than the use of plant drugs. Fat and grease from various animals are frequently mentioned for incorporation in various prescriptions, both for oral administration and for application to the skin. Thus goose-fat is found in prescriptions for internal use to remove pain, and is also recommended to be applied to the body externally for relaxation. Blood, bone-marrow, bile, liver, and spleen are all recommended for various disorders, but with little evidence of rationality in the light of modern knowledge. For example, liver is incorporated in prescriptions to prevent grey hair, and blood is advised for baldness. Excrements of various animals appear occasionally. These are incorporated in prescriptions for the relief of throbbing in limbs or for applications to promote relaxation. These materials do not seem to have been employed to drive out evil demons, the most common use for them in primitive folk-medicine.

Wax is extensively recommended in the Egyptian medical papyri for use as a vehicle or binding material, in various ointments or preparations for applications to the skin or wounds. A number of alkaline powders are recommended, to be derived from such sources as wall-brick, limestone, builder's lime, clay, and gravel. Soot and charcoal are recommended for skin applications, burns, or itchings.

Doctor Sanford Larkey has made an exhaustive study of the different diseased conditions in which the various drug materials are recommended. It is his opinion that there is consistency in the type of use recommended, and a considerable degree of appropriateness on an empirical 
basis, even in the light of modern knowledge. In general there seems to be an affirmative answer to the question whether there is evidence that the Egyptians made a rational application of the biological actions of the drugs which they used.

Another interesting question is: What relation has the crude drug-lore of the ancient Egyptians to the extensive empirical materia medica which accumulated in Western civilization, to reach its climax in the 18th century and finally to be demolished by the rise of chemistry in the 19th? This question may be investigated by examination of such works as Dioscorides' De re materia medica, numerous editions of which are readily available, and particularly by a study of Francis Adams' comprehensive commentary on the materia medica of the classic Greek, Latin, and Arabic medical writers. Subsequent uses of the same crude-drug preparations may be traced through the many medical formularies and recipe books of the Middle Ages and the Renaissance. They may even be traced into modern pharmacopoeias and dispensatories. Many of the recommendations made for these crude drugs by the classical physicians, as well as by medieval and later writers, correspond to the uses recommended by ancient Egyptians, as far as can be determined from an analysis of the medical papyri.

The very organization of the many medieval formularies, such as the popular compilation of the mysterious Mesue, as well as many of the popular 16th and 17th century English formularies, are similar to the make-up of the Hearst and the Berlin Medical Papyri. That is, they are essentially collections of recipes for the treatment of 
symptom complexes, or diseases. Many medieval medical formularies are more systematically arranged for textbook use, as in the case of the Ebers Medical Papyrus. A much more scientific method of organization was developed by Dioscorides in Roman times. This was to deal comprehensively with each separate medicinal agent. Each was described so that it might be properly identified, its sources recognized, and for each a description was made of the preparation of the parts to be utilized for medicinal purposes. The action of the material was sometimes briefly stated, and the medicinal uses to which it might be put were discussed. Finally, the ways in which it might be prepared for administration were given, together with dosage. This is the method followed by modern pharmacopoeias.

Some interesting confusions, which seem to have arisen from antiquity, persist through this traditional corpus. Thus there appears in the Egyptian papyri a material transliterated as prš. The determinatives indicate that this agent was reddish and granular. It is usually identified by the translators with "dragon's blood." What was called "dragon's blood" through all the Graeco-Roman period and even in medieval and recent times was never clearly differentiated between cinnabar, or red mercuric sulphide, and Resina draconis, derived from Calamus draco, an East Indian palm tree. The first is an astringent red metallic compound, while the latter is an astringent red resin. The hard character of the two products, as well as the color, and the powdered form in which they may have been prepared, probably made separation or distinction difficult. At any rate, the confusion appears to have existed since 
antiquity. It has recently been discussed by Doctor Torald Sollman.

The therapeutic procedures of the ancient Egyptians, as far as can be determined from the old papyri, were essentially empirical and apparently quite appropriate for the purposes for which they were designed, in view of the probable state of knowledge at the time. The crude plant, animal, and mineral drugs identified in the papyri are generally such as have a physiological action which may have been readily observed in the course of accidental contact with them or on trying them for food. A remarkable number of the identified crude drugs recommended in the old Egyptian medical papyri may be traced through Greek, Roman, Arabic, and medieval medical writers to the 19th century, when the rise of modern chemistry and pharmacology subjected all the extensive materia medica of the past to systematic analysis, with the result of discarding most of it in favor of such pure chemicals as could be shown to be best suited for clinical use. 


\section{The Hearst Medical Papyrus}

E

ighteen coarse, brown, and frayed sheets of papyrus, covered with heavy black and red hieratic script, and comprising a series of medical prescriptions, were acquired by the University of California as a result largely of the enlightened philanthropy of Mrs. Phoebe Apperson Hearst (1842-1919). Mrs. Hearst's enthusiastic interest in promoting the intellectual prestige of the University, which she served so faithfully as a Regent from 1897 to 1919, led her to finance an Egyptian Expedition from 1899 to 1905 for the purpose of obtaining archaeological material for an Anthropological Museum in the culture-thirsty West. This expedition was under the direction of the distinguished Egyptologist, Doctor George A. Reisner, who was the Hearst Lecturer in Egyptology at the University of California at the time.

In his account of the document, Doctor Reisner states, "In the spring of 1901, a roll of papyrus was brought to the camp of the Hearst Egyptian Expedition near Dêr-el-Ballâs, by a peasant of the village as a mark of his thanks at being allowed to take sebah from our dump-heaps near the northern kom." When questioned, the peasant stated "that he had found the roll while digging for sebah two years before, that he had put it away in a cupboard in his house and forgotten it." When pressed further, he said that the roll was discovered "in a pot among the house walls between the southern kom and the southern cemetery." Reisner goes on to say that the roll was brought to the camp "tied up in the end of a native head-cloth 
(šga), and had, of course, been carried in a similar manner from the place where it was found to the village. The damage done to pages XVI to XVIII which were on the outside of the roll was due to this treatment."

On examining the papyrus, Reisner noted that "the roll had not been opened since antiquity as was manifest in the set of the turns, the fine dust, and the casts of insects. The beginning of the roll was inside. In the middle. of the first page preserved, the papyrus has been torn in two in antiquity and rolled up with the torn page inside."

Toward the close of the expedition, Reisner prepared and published a brief account of this document, and named it "The Hearst Medical Papyrus" in honor of Mrs. Hearst. This account contains a glossary of terms, compiled by Kurt Sethe, a preliminary analysis and translation of prescription headings, and photographic reproductions of the eighteen sheets. Under the direction of Professor Edward W. Gifford, Curator of the Anthropological Museum of the University of California, the sheets or "columns" of the papyrus were hermetically sealed between glass plates for proper preservation. For years they were displayed in the Egyptian Antiquities Room of the Museum on Parnassus Heights in San Francisco. When the building was torn down in 1933 to make way for the University of California Clinics, the Museum collections were moved to storage in Berkeley, where they have since remained.

At the meeting of the American Association for the Advancement of Science in Berkeley, June 18-23, 1934, Doctor Herbert M. Evans, Professor of Anatomy and Director of the Institute for Experimental Biology, Uni- 
versity of California, arranged an exhibit of first editions of classics in the history of science, with which the Hearst Papyrus was displayed and described.

Meanwhile in 1912, Walter Wreszinski of Königsberg published his scholarly, highly accurate, and conservative hieroglyphic transcription and partial translation of the Hearst Medical Papyrus into German. To the brilliant work of Wreszinski in this and similar efforts relating to the Berlin, London, and Ebers Medical Papyri, all students of Egyptian antiquity will owe increasing debt.

Since 1930 Doctor Henry F. Lutz, Professor of Semitic Languages at the University of California, Doctor Sanford V. Larkey, now Librarian of the Welch Medical Library of Johns Hopkins University, Baltimore, and myself, have been studying the Hearst Medical Papyrus. A full English translation has been prepared, with extensive annotation regarding the diseased conditions described and the drugs recommended. This material is in continuous process of revision. Tentative generalizations are reported here. 


\section{Organization of the Hearst Medical Papyrus}

I

$t$ is at once clear from an examination of the contents of the Hearst Medical Papyrus that no systematic organization was followed by the scribe. Groups of related prescriptions are placed without any reference to logical sequence or orderly arrangement. The most reasonable explanation of the organization of the papyrus is that the scribe copied it from several different sources. It would seem that some physician from the country had come to a medical center, and had employed a scribe to copy for him from whatever sources available a series of useful prescriptions for various diseased conditions with which he might be concerned. However, since the beginning and ending of the document are lost, there might have been some clue to the organization of the material which is not now apparent from an examination of its contents.

In the Hearst Medical Papyrus one may find a few prescriptions grouped together for a common purpose, to be followed by a number for a totally unrelated use. Occasionally a prescription for an entirely different matter appears in the midst of a group of related prescriptions, There is indication that some sections may have been . grouped together in other documents and introduced by a series of "recitals." The "recitals" in Hearst 212-217 precede a series of prescriptions relating to the treatment of broken bones.

Over a third of the 260 recipes in the Hearst Medical 
Papyrus are to be found in the Ebers Papyrus. Similarly a considerable number of prescriptions in the Hearst Medical Papyrus are identical with, or similar to, prescriptions in the Berlin Medical Papyrus. It is clear from the hieratic script of the Hearst Medical Papyrus, and the character of its contents, that it was composed at about the beginning of the great XVIII Dynasty, or at the same time as the Ebers and Berlin documents.

The general style of the organization of the Hearst Medical Papyrus may briefly be indicated by a consideration of its contents. Its frayed and fragmentary first sheet opens with three prescriptions for purging, followed by four prescriptions for anal conditions, and then by two prescriptions for mouth afflictions. Then comes the important series, prescriptions 10-15 (following Wreszinski's numbering), for broken bones, which are more extensively discussed later in prescriptions 217-227. In the midst of four prescriptions $(16,18,19,20)$ for expelling noxious materials is an ointment for dandruff. Prescriptions 21-23 are for insect bites, while prescription 24 appears to be for lice. These are closely similar to the Ebers series of prescriptions numbered $432-437$.

One might think that there would be some evidence of similarity of material on each of the separate sheets or "columns." However, this is not the case. Thus, the second sheet opens with a continuation of prescription 16 from the first sheet, is followed by prescriptions for dandruff, internal ailments, bites, and pains in the body. The series of prescriptions 25-30 deal with expelling pains within the body, and are immediately followed by prescription 31 "to remove bad odor in summer." 
This prescription (similar to Ebers 708 and Hearst 150) concludes the bottom of the second sheet of the papyrus, and goes over to the first line of the third sheet.

Hearst prescriptions 39 and 40 "to alleviate burns" are identical with Ebers 537 and 538. These recommend mucilaginous poultices and saline applications.

The arrangement of related prescriptions in the Hearst Papyrus does not always follow the same order as that in which the same prescriptions occur in the Ebers Papyrus. Thus, the Hearst prescriptions 63-66 are identical or similar to the Ebers series 277-280. However, Hearst prescription 65 is similar to Ebers 280, while Hearst prescription 66 is identical with Ebers 279.

The complex prescriptions in Hearst which are numbered 71-75 deal with recommendations for application by bandage for expelling pains in the head. The headings are semi-religious, and suggest divine authority on the basis that the prescriptions were made by specific gods. This series is similar and occurs in the same order as the Ebers series 243-249. The Hearst material numbered 78 is a "recital" for the application of a remedy to a limb, and occurs at the beginning of the Ebers document. This is followed in Hearst by a series of prescriptions (79-84) for expelling fluid accumulation from the body. This series is similar to and retains the same order as the Ebers series 221-226.

The Hearst prescriptions $89-92$ deal with the treatment of skin abrasions or contusions. They recommend the application of moldy bread crumbs, salt, and rags. Here one may assume an ancient observation on the possibility of molds being helpful in preventing skin infections in con- 
nection with abrasions. This is a long way from the modern antibiotics, but it suggests the same sort of observational skill.

Hearst prescription 94 is headed "The Beginning of the Treatise for Alleviating Any Disease." It then goes on to give a prescription to ease $m t . w$. There follows a long series of complex prescriptions, many of which are related to scattered prescriptions in Ebers. The Hearst series runs from prescription 95 to 122 . Most of these prescriptions are to be applied with bandages, and they imply ointments. They suggest remedies for what might be considered arthritic or rheumatic pains. Such conditions must have been common in ancient Egypt, to judge from skeletal remains. The term $m t . w$ apparently refers to the muscles, or to the vessels. Considerable discussion has occurred regarding its precise meaning. Another series of prescriptions to soothe $m t . w$ occurs in the Hearst document from prescription 228 to 238 . Some of these are similar to the earlier series, and others are like those found in scattered places in the Ebers Papyrus.

Hearst prescriptions 127-141 appear to deal with local application for boils, ulcers, and "swellings." These are mostly astringent alkaline poultices and are related to the Ebers prescriptions from 556 to 591. It is difficult to appraise Hearst prescriptions 142 and 143, one "to cause anything to be active" and consisting of an oily mixture to be taken orally for four days (identical with Ebers 695), and the other "to expel a pool of blood when it is not yet clotted," similar to Ebers 593, and comprising a quantitative plant mixture to be taken by mouth for four days. 
The latter may refer to the management of an internal hemorrhage or peptic ulcer.

The lack of organization in Hearst is now immediately apparent when one considers that the next group of prescriptions, from 144 to 149 , refer to ointments for growing hair or preventing grayness. Prescriptions 150 and 151 are to expel bad odors, and consist of aromatic ointments, similar to Ebers 708 and 711 .

Following a prescription to purge the body, identical with Ebers 713 (prescription 152) Hearst goes on with a series of cosmetic prescriptions (153-158) to improve the skin and to treat baldness. Similar to Ebers 474 and 475 respectively, Hearst 157 and 158 are oily materials to be applied locally. Hearst prescription 157 runs over from the bottom of sheet 10 to the top of sheet 11 . These two prescriptions are followed by a number of prescriptions for uncertain conditions. Prescription 159 is similar to Ebers 733 and consists in the application and administration of beetle parts in oil for expelling "evil." Hearst 160 is an abjuration against the mśpn.t disease. Six separate prescriptions are given for this unknown condition. In each instance the prescriptions contain mild alkaline fatty material for local application. A series of similar prescriptions appears for a group of unknown diseases in Hearst 167-172. None of these prescriptions in Hearst from 160 to 172 occur in the other medical papyri.

A long series of prescriptions for finger and toe conditions, probably localized in sections around the nails, occurs in Hearst from 173 to 203. Most of these are mucilaginous poultices or mild astringent mixtures. Several are 
similar to prescriptions for like purposes occurring in Ebers.

On sheet 13 of the Hearst Papyrus appears a series of six prescriptions (206-211) for nsj.t, which implies "heat" or "burning." The first five are similar to the Ebers series from 751 to 756, but do not come in the same order. The drugs are chiefly plant mixtures for oral administration in beer, and suggest remedies for fevers. Certainly fevers, especially malaria, must have been common in ancient Egypt.

On the bottom of sheet 13 of the Hearst Papyrus and running over to sheet 14 is a series of five "recitals" (Hearst 212-215). The first two are to be said in connection with measuring utensils, and seem to be reminders for care in accuracy of measurement. The other three are supplications for the efficacy of oil, honey, or beer, suggesting stage directions for inspiring confidence in the patient. These are followed by a series of eleven prescriptions for mucilaginous casts to be applied with bandages for broken bones. The first five are similar to the Hearst series 10-14.

On sheet 15 of the Hearst Papyrus there is further repetition. This refers to a series of prescriptions for soothing $m t . w$, for casts for broken bones, and prescriptions for boils or tumors. Many of these are similar to earlier prescriptions in Hearst, and also to other prescriptions occurring in Ebers.

On sheet 16 of the Hearst Papyrus may be found a series of prescriptions for treating bites made by animals (prescriptions 239-244). These are clearly indicated to be for the treatment of bites caused by crocodiles, pigs, hippopotami, and lions. 
The rest of the Hearst Papyrus is fragmentary, but includes some prescriptions for soothing $m t . w$, for the treatment of wounds, or for the management of other local conditions to be handled by local applications.

It is clear that there is no clear, consistent, satisfactory organization in the Hearst Medical Papyrus. There is, nevertheless, grouping of prescriptions for specific conditions. It is remarkable that there should be clear repetition of prescriptions for similar conditions such as broken bones. One may only conclude that the scribe copied from various sources without reference to grouping the material for the convenience of the physician for whom the compilation was made. He may not even have realized that he was sometimes repeating what he had already copied. The lack of any index for locating material must have been as confusing anciently as now. It is amazing that indexes or tables of contents developed so slowly in connection with reference documents, particularly such as were concerned with many confusing recipes for treating disease. 


\section{Diseases in the Hearst Medical Papyrus}

A

$s$ the formulary of a practicing physician in ancient Egypt, the Hearst Medical Papyrus does not deal with the examination of patients, nor with diagnosis. Prescriptions are offered for diseases which are named and indicated. It is thus assumed that the physician has examined the patient and reached a diagnosis. The various recipes in the papyrus are offered as a guide for treatment.

In the analysis of the diseases in the Hearst Medical Papyrus, as undertaken by Doctor Sanford V. Larkey, one may recognize several categories: (1) internal diseases, such as urinary disorders, fever, purgation, or ailments of the heart or stomach; (2) skin involvements, including boils, ulcers, tumors, contusions, wounds, and irritation of the anal region; (3) orthopedic conditions, including ailments of bones, joints, and muscles; (4) cosmetic recipes for the skin, head, hair, and teeth; (5) the "recitals," and (6) the incomplete prescriptions.

These various disease categories are scattered throughout the Hearst document. On further examination, however, certain groupings become apparent. One may speculate from the way in which the prescriptions are grouped that they were copied from many different sources, probably monographic treatises. Is this evidence of medical specialization?

If one considers the internal disorders treated by oral administration of various drugs, as the prescriptions are 
grouped in the Hearst Papyrus, one finds certain sequences. There are four prescriptions to treat constipation. The headings for these prescriptions are usually "For

\section{Table 10}

Main Types of Diseases Indicated in the Hearst Medical Papyrus

General Category

1. Internal Disorders, treated by oral administration

2. Cutaneous Disorders, treated by local application

3. Orthopedic Conditions, treated by local application

4. Cosmetic Matters, handled by local application

5. Recitals
Specific Indication

Constipation; stomach disorders; heart disease; urinary disorders; dropsy; fevers; sickness and malaise.

Pruritus; insect bites; boils; burns; contusions; animal bites; wounds.

Fractures: pains in the limbs, head injuries; $m t . w$; diseases of joints; mspn.t; tmj.t; finger- and toenails.

Teeth; dandruff and lice; body odor; hair; skin.

Adjurations; for care in measuring.

Purging the Body." They comprise prescriptions 2, 3, 58, and 152, as numbered by Wreszinski. There are several prescriptions for stomach disorders. These are 48, 49, 50, and 61. Prescriptions 51 and 52 are for heart disease. There follow a considerable number of prescriptions for the treatment of urinary disorders (59-70). The series of prescriptions from 79 to 87 deal with conditions which may be interpreted as dropsy. There is then a considerable number of prescriptions for "dispelling evil," which may be regarded as remedies for the relief of general malaise or sickness or anorexia. These prescriptions are 16, 18, 36, 54, 129-131, 142, and 143. Toward the latter part of the Papyrus is a group of prescriptions for treating nsj.t, which may be interpreted as "fevers." This series includes prescrip- 
tions 206-211. Of the sixty-five prescriptions for oral administration for internal disorder in Hearst, 53, or 81 per cent, are quantitated.

There is a similar scattered distribution of prescriptions for various cutaneous conditions in the Hearst Papyrus. Thus, prescriptions 4,7 , and 93 give remedies for irri-

\section{Table 11}

Internal Disorders Indicated in the Hearst Medical Papyrus

Remedies prescribed for oral administration, 80 per cent quantitated

Diseases Indicated

Constipation

Stomach Disorders

Internal Ailments, Visceral Pains

Hematuria

Urinary Disorders

Heart Disease

Dropsy (Fluid Accumulations)

Epilepsy (Seizure, Spell)

General sickness, malaise, "Evil"

Fevers (nsj.t)
Prescriptions, Numbered by Wreszinski

$2,3,58,152$

$28,48,50,61,88$

$26,29,30$

18

$59,60,62-70$

$51-52$

$79-87$

$36,54,55$

$16,53,129-131,142,143,159$

206-211

tations of the anal region. Recipes for application to insect bites are considered in prescriptions 21-23. Remedies for boils, abscesses, and carbuncles are offered in prescriptions 35, 132-141, 235, and 236. Two prescriptions are specifically designed for burns, 39 and 40. Contusions, skin abrasions, and ulcerated conditions are the subjects for prescriptions in the series $89-92$. Animal bites are treated by remedies recommended in the series numbered 239-244. Wounds in general, either caused by accident or in fighting, are the 
subject of the prescription series 245-248, and also of prescription 260.

In most cases of cutaneous affliction in the Hearst Papyrus, the remedies recommended are mild alkaline, astringent, and antiseptic mixtures for local application. Most

\section{Table 12}

Cutaneous Disorders Indicated in the Hearst Medical Papyrus

Treated by local application, 34 per cent quantitated

Disorders Indicated

Pruritus

Insect Bites

Boils, Carbuncles

Burns

Contusions

Animal Bites

Wounds
Prescriptions Numbered by Wreszinski

4,7

$21-23$

$35,132-141$

39,40

89-92

239-244

$245-248,260$

of the ingredients are relatively straightforward plant and mineral materials which would have bland, soothing, or mildly astringent action. Except for the prescriptions dealing with contusions and burns, a bare majority of the recipes for cutaneous ailments are quantified.

Hearst prescriptions 140 and 141 directly indicate that they are designed "to bring forth pus." These prescriptions are quantitated and may call for one $k d . t$ (9.5 gms.) of each ingredient. Both prescriptions contain frankincense and alkaline astringents with plant material for bandaging over the abscess or ulcer.

Doctor Robert Steuer has brilliantly discussed the etio- 
logical principle of pyaemia ( $w h d w$ ) in ancient Egyptian medicine. (To this, reference occurs in Hearst 138.) Doctor Steuer's discussion is the most significant so far offered for an appreciation of the etiological concepts of the old Egyptian physicians concerning internal diseases. After showing the association of excrement with whdw, Doctor Steuer analyzes Egyptian ideas on the formation of pus and indicates their significance for recommended therapy. He concludes that the ancient Egyptians realized that the complete elimination of pus is essential to achieve lasting healing. According to Doctor Steuer's theory, sfwt, the abscess or swelling referred to in Hearst prescriptions 138 and 139, would be evidence to the old Egyptian physicians, of a blood disease, and specifically pyaemia, or pus in the blood. Doctor Steuer points out that the ancient Egyptian idea of suppuration was related to the idea of $m t w$ (muscles, blood vessels), coagulation, wound healing, and mummification.

A rather large number of prescriptions, dealing with local applications of material for casts, or for astringent and soothing action, can be grouped together in relation to disorders of the extremities. These include recipes for casts for the management of fractures as indicated in prescriptions $10-15,217-227,233$, and 234 . The rather vague condition of "pains and sickness in the limbs," which may refer to arthritic conditions or muscle injuries, is considered in prescriptions 33, 34, 37, the series from 41 to 46, the group from 125 to 130 , and 138. The unusual series of prescriptions numbered 71-74, giving divine authority for recipes for local applications for diseased conditions in the limbs, seems to have been taken from a single source 
which may have been devised for popular use. Applications for head injuries, or for headache, are considered in prescriptions 75-77. Two important series of prescriptions, 94-122 and 228-238, refer to the treatment of $m t . w$, which is a term for afflictions of muscles or vessels. Since the term is often used with the qualification "throbbing," a likely interpretation is arthritis or rheumatism, which

\section{Table 13}

Bone, Joint, and Muscle Disorders Indicated in the Hearst Papyrus Treated by local application, 44 per cent quantitated

Disorders Indicated

Fractures

Pains and Illness in the Limbs (arthritis?)

Afflictions of Limbs (with divine authority and all quantitated)

Head Affliction

$m t . w$

Diseases of Joints

mspn.t

tmj.t

Fingers, toes, nails
Prescriptions

Numbered per Wreszinski

$10-15 ; 217-227,233,234$

$33,34,37,41-46,125-130$

$71-74$

$75-77$

94-122; 228-238

123,124

160-166

168,169

$173-205$

must have occurred as frequently in ancient Egypt as now. Prescriptions 123 and 124 refer directly to the management of diseases of joints. Here may be meant arthritic deformity. The Hearst series of prescriptions from 160 to 166 deals with the diseased condition transliterated as mspn.t. Since these prescriptions include mild alkaline astringents, with fat for local application, it is reasonable 
to conclude that the disease referred to is some muscle or subcutaneous soreness or involvement. The same considerations apply to the disease transliterated as $t m j . t$ which is considered in prescriptions 168 and 169.

In the Hearst Medical Papyrus, a considerable number of relatively reasonable prescriptions are offered for the management of bone, muscle, and joint conditions, recommending mild alkaline astringent plant and mineral materials either for inunction when incorporated in grease or fat, or for application with a bandage. Relatively few of the prescriptions for these conditions are quantitative.

A few prescriptions scattered through the Hearst Medical Papyrus may have been offered primarily for cosmetic purposes. Two, however, which deal with teeth (prescriptions 8 and 9), may refer to scurvy or some other oral con-

\section{Table 14}

Cosmetic Recipes in the Hearst Medical Papyrus

For local application, 17 per cent quantitated

\section{Purpose}

Control dandruff, lice

Control body-odor

Improve hair

Beautify skin
Prescription Numbered per Wreszinski 17,24

$31,32,150,151$

$144-149 ; 155-158$

153,154

dition involving the gums. Prescription 17 is for the relief of dandruff, while prescription 24 seems to have been devised to remove lice from the scalp. Prescriptions containing aromatic ingredients $(31,32,150$, and 151) are offered for the removal of body odor. That vanity was a significant 
factor among the old men of Egypt, even as now, is evident from the prescriptions in Hearst (144-149; 155-158) for treating baldness or for preventing gray hair. For beautifying the skin, a matter in which the ancient Egyptian women may have been as much interested as their sisters now, the Hearst prescriptions 153 and 154 offer encouragement. The occurrence of so many of these cosmetic recipes (prescriptions 150-158) in one place in the Hearst Papyrus suggests that they were all taken together from a treatise dealing primarily with this sort of material.

The eight "recitals" in the Hearst Medical Papyrus form the chief basis for criticism of the document as "magical." This is too sweeping an allegation with respect to the treatise as a whole, and unwarranted in view of the relatively rational character of the bulk of its material. On the other hand, three of the "recitals" may well be openly admitted to have "magical" implications. The first of these (numbered 78) occurs at the end of the group of "popular" recipes for local application to afflicted limbs, which are offered with divine sanction (prescriptions 71-74) and the two prescriptions (76-77) for application to the head. This "recital" is designated "to be spoken during the application of the prescription to any limb which is sick: something really tested millions of times." This appears to have been designed for popular appeal. A similar consideration may apply to the "recital" to expel fluid accumulation (dropsy), which occurs at the end of prescription 85. The "recital against the Asiatic disease" (number 170) seems likewise to be designed for popular encouragement in connection with the remedies proposed.

On the other hand, the series of "recitals" for measur- 
ing utensils and vehicles (numbers 212-216) seems to have been designed to focus the attention of the physician or the pharmacist on the necessity for care in measuring. The "recital" numbered 212 may furthermore have been a reminder to the physician regarding the symbolism in the divisions of the $h k . t$ with reference to the well-known legendary "Horus Eye." In the "recitals," numbers 214216 , for oil, honey, and beer, there is again the suggestion of "magical" implication. In general, however, none of these "recitals" may be considered to be any more superstitious or magical than the prayers which are still customary in Western culture in connection with the treatment of disease.

There remains a group of prescriptions in the Hearst Medical Papyrus which are either incomplete or difficult to classify because of doubt or complete lack of knowledge regarding the diseased condition to which reference is made. While some of the prescriptions on the first sheet of the existing Hearst Papyrus are incomplete, others can be classified in accordance with context. At the end of the document, most of the prescriptions are incomplete and are unsatisfactory for comment either with regard to the disease concerned or to the drugs proposed.

There are, then, a number of miscellaneous prescriptions from which it has not been possible to identify the disease. An example is Hearst 38 for $s^{c} s . t$. This is to be treated by local application of a mucilaginous poultice, and thus may be reasonably supposed to be a local skin irritation of some sort. Hearst prescription 27, "To Expel the hn.w of the Legs" contains vegetable ingredients in oil, honey, and water, to be taken by mouth. The character 
of the ingredients is similar to those recommended for expelling fluid accumulation. The condition referred to may have been edema of the legs. The sspn sickness for which the remedies are recommended in Hearst prescription 172 may have referred to some sort of rhinitis, since the ingredients, peppermint in water, are to be rubbed on the nose. In Hearst prescription 171 reference is made to the irwtn disease, which is to be treated by oil administration of peppermint in wine; and the prescription concludes with the recommendation that "a cutting of the lower part of his leg is to be made." This may refer to

\section{Table 15}

\section{Miscellaneous Conditions Indicated in Hearst Papyrus}

Indication

Loose teeth, bloody gums

whi, "rumbling within"

$h n^{\mathrm{c}} w$ of legs

$\xi c \tilde{s} . t$

Cure for the lung

Cool the anus

"Bitterness"

irwtn, šspn

Recitals for utensils and vehicles
Prescription

Numbered by Wreszinski

8, 9 (Quantitative applications)

19, 20 (Blood by mouth)

27 (Quantitative by mouth)

38 (Poultice)

57 (Quantitative by mouth)

93 (Quantitative by mouth)

131 (Given orally)

171, 172 (Note Quantified)

212-216

blood letting, or may indicate that the disease involves edema of the legs. There is no indication of the character of the disease called whj to which reference is made in Hearst prescription 19, and for which bull's blood by mouth is recommended. 
On the whole the diseases to which reference is made in the Hearst Medical Papyrus are those which might ordinarily be expected to have been noticed by a relatively observant group of physicians under relatively primitive conditions. With no satisfactory general etiology for internal ailments, there could be no effective understanding of symptoms, and thus no satisfactory diagnosis. On the other hand, the realization of the etiological principle of pyemia (wdhw) as indicated by Doctor Robert Steuer, was a considerable achievement on the part of the ancient Egyptian physicians, and enabled them to rationalize therapeutic procedures for abscesses, ulcers, wounds, and even to preserve the body from suppuration in mummification. Empirical observation, however, must have led them to apply effective crude drugs to these uses. 


\section{The Ingredients of the Hearst Papyrus Prescriptions}

\section{I}

scriptions one is immediately impressed by the small number remaining wholly unidentified. Of two hundred separate materials there are only some eight which are as yet without any sort of identification. It is interesting that nearly half of the ingredients of the prescriptions are of plant origin. Of these about half have been satisfactorily identified. The remainder of the plant ingredients are only partially identified, being known to be of plant origin and to refer to some part of a plant, such as seeds, leaves, or fruit.

The most widely used of the plant ingredients of the Hearst Medical Papyrus is the gourd $(d r . t)$, which is prescribed in thirty-three cases. It is not clear whether $d r . t$ refers to the ordinary edible gourd, or to the bitter gourd, which is colocynth, and which has a purgative action. Some light may be shed on the problem by a consideration of the purposes for which gourd or gourd seeds are recommended. Only five of the Hearst prescriptions in which gourd seeds are specified are to be administered by mouth. Three of these, numbered 29, 48, and 83 , are carefully quantitated, and deal with the removal of noxious materials from the body. In these three prescriptions, colocynth, as a bitter purgative, might have contributed to the desired effect. In the Hearst prescriptions 131 and 211 gourd seeds appear without quantitative specification, but also for use in mixtures for expelling noxious matter. In the rest of 
the prescriptions in Hearst in which gourd seeds or parts of the gourd occur, the indication is for local application to an irritated part. In these instances the material from gourds would probably act as a bland pasty material to assist in the formation of the desired poultice.

Acacia is recommended as an ingredient in Hearst prescriptions in twenty instances. In seventeen it is incorporated in a mucilaginous paste or poultice for local application or binding. Here the soothing character of the gummy material might have been helpful for the conditions in which its use is recommended. In Hearst prescriptions 47,83 , and 152, acacia is recommended for inclusion in a quantitative recipe for internal use. Hearst prescription 152 is specifically indicated to be for "purging the body." Acacia has little such action, except through bland bulk. However, in Hearst prescriptions 47 and 83, the acacia may have been combined with the other ingredients of the prescription to alleviate local irritation in the intestinal tract, as apparently desired.

Several long-used carminative drugs appear as ingredients in the Hearst Papyrus prescriptions. Anise is recommended in quantitative prescriptions for internal administration in Hearst 28, 50, and 84. The well-recognized carminative action of anise would be appropriate for the purposes indicated in these prescriptions. Both coriander and cumin have a long history in Graeco-Roman and medieval medicine as cooling and astringent agents, and they are so recommended in a number of Hearst prescriptions for local application to irritating or injured parts. They also possess carminative action when given internally, and 
again are so recommended in Hearst prescriptions where such action would be indicated.

Barley, beans, peas, and wheat are recommended in many Hearst prescriptions for external application in connection with mucilaginous poultices for soothing or mild astringent effect. Cinnamon is similarly recommended in six prescriptions. Cinnamon was apparently one of the drugs introduced from the celebrated expedition to Punt in the XVIIIth Dynasty.

The well-recognized mild purgative action of figs seems to have been rationally employed in a number of Hearst prescriptions, such as the series 28-30, "To Cure the Left Side" or "To Break up Pains within the Body." Figs are similarly recommended in quantitative prescriptions for removing noxious matter from the body, as in Hearst prescriptions $56,57,70$, and 84 .

Garlic and leek are recommended for local application to insect bites and to skin irritations. The mild astringent and antiseptic action of the active agents in these materials may have been appropriate for the purposes indicated, as pointed out by Sigerist.

Juniper berries have long enjoyed a reputation for mild diuretic action. It is interesting that they are recommended in so many of the Hearst prescriptions which were to be used for urinary disorders, or for expelling fluid accumulation. Juniper is found as an ingredient in twenty of the prescriptions, most of them apparently devised for diuretic effect.

The well-known purgative action of castor oil does not seem to have been appreciated by the ancient Egyptians. On the other hand, castor plant petals or leaves are recom- 
mended as ingredients in Hearst prescriptions 62 and 82, which have the purpose of promoting urination or expelling fluid accumulation. Castor is also recommended for inclusion in mucilaginous poultices for bandaging (Hearst prescriptions 103 and 169).

Dates are also recommended as ingredients in the Hearst prescriptions for inclusion in quantitative recipes for oral administration for diuretic purposes or for assisting in expelling fluid accumulations. In addition they are advised to be incorporated in mucilaginous poultices for soothing applications locally. Dates are included as ingredients in fourteen Hearst prescriptions.

It is not possible to obtain satisfactory indication from the purposes of the prescriptions for the possible identification of the unknown plant remedies which are noted so frequently. Some, like $\xi^{y} s$ ' kernels, occur like dates, in prescriptions both for internal use for getting rid of excess fluids, and also in prescriptions for local application in mucilaginous poultices. This knowledge is not particularly helpful in specific identification.

Analysis of the drugs and diseases mentioned in the old Egyptian medical papyri is handicapped by lack of organization and indexing. It is not likely that ancient Egyptian physicians could find what they sought in the scrolls any more quickly than modern scholars seeking a particular prescription or drug or disease in them, even with a specially prepared index! It is amazing that the problem of how to find what we know, is so ancient!

Much study remains to be done on the various plant remedies recommended in the Egyptian medical papyri. For example, is there evidence that opium was used to re- 
lieve pain? So far the answer is no. Poppy seeds seem to have been used as carminatives. Opium, with its active alkaloids, can only be obtained by natural drying of the juice of the unripe seed-capsule of the poppy. This was apparently not known to the old Egyptians. Again, it is interesting to follow the continued use of many of the plant ingredients through Graeco-Roman and medieval formularies into current use. This is particularly striking 'with such drugs as the carminatives, anise, coriander, and cumin, and with juniper berries for diuresis.

Although the number of resinous ingredients in the Hearst Papyrus is relatively small, comprising about twelve identifiable materials, they are of great importance. Among the most effective of the locally applied astringent antiseptics used by the ancient Egyptian physicians were frankincense, gum, and myrrh. Frankincense is specifically used as an ingredient in forty-five prescriptions, while myrrh is specifically recommended in nineteen.

Some twenty ingredients of mineral origin are specified in the Hearst Papyrus. Most of these again are useful as locally acting mild astringent antiseptic agents. Salt is specified in thirty-two prescriptions, many of which are alternates for those in which frankincense or myrrh is indicated. Natron ( $h s m n$ ), or sodium carbonate, is specified in nineteen prescriptions.

Materials from animal sources comprise some twenty ingredients of the Hearst Papyrus prescriptions. The most frequently used is fat, recommended in nineteen prescriptions, which are devised as ointments. Goose fat is specifically designated in ten prescriptions. Among ingredients 
from animal sources are included three invertebrates (beetles and worms) and four fish.

Approximately two dozen kinds of beverages and foodstuffs are included as ingredients in the Hearst Papyrus prescriptions. The beverages, of course, are chiefly employed as vehicles. Beer is the vehicle in twenty-seven prescriptions. In eleven prescriptions, milk is the vehicle. Wine is used as the vehicle in twelve. Honey appears as an ingredient in seventy-seven prescriptions-the most commonly used agent in the Hearst document. It frequently occurs in many consecutive prescriptions in a series, for example, in the prescriptions numbered from 199 to 204, a series for treating afflictions of toenails. Oil (mrh.t) is an ingredient in forty prescriptions. Water is the vehicle in twenty-four. In nineteen, wax is included, probably for the purpose of binding the rest of the materials together.

Among miscellaneous ingredients in the Hearst prescriptions are charcoal, clay, leather, rags, "scrappings of jars," soot, and even "hot water of the washerman." Soot (bd.t) occurs in four prescriptions. Urine is mentioned only once (prescription 39), but excrements are specified in six.

Some of the ingredients in the Hearst Papyrus are not satisfactorily classified. For example, "dragon's blood" (prs), which occurs in prescriptions 104, 124, and 229, may be either cinnabar, or red mercuric sulphide, or, on the other hand, Resina draconis from an East Indian palm tree. This confusion regarding "dragon's blood" has persisted in European formularies through medieval to relatively modern times.

Thanks to the careful studies of such skilled Egyptolo- 
gists as Warren R. Dawson, Alan Gardiner, and E. Ebbell, the number of wholly unidentified ingredients of the Egyptian Medical Papyri is relatively small. In some instances the determinatives indicate whether the material is liquid or oily. Some of these identified ingredients may have had conventional names. An example is $i b r$ ointment, which occurs in Hearst prescriptions 123, 194, and 216.

Before one may draw any satisfying conclusions regarding the rationality of the recommended therapeutic uses of the various ingredients of the old Egyptian medical prescriptions, it is wise to consider again some of the difficulties involved in translation and identification. The problem is largely concerned with probabilities, and the extent to which agreement can be reached among competent scholars. Many factors must be considered in each instance. Reliance on plausibility of conjecture is evident in many of the recent discussions on this matter. Victor Loret provided the chief basis for the identification of plant materials. More recent studies have been concerned with discussions of the mineral ingredients and of material from animal sources.

Taken as a whole, however, certain generalizations may be reached: (1) the relatively large number of drugs recommended by the old Egyptian physicians for the treatment of various diseased conditions seem to have a rational basis in sensible applications to diseased conditions of readily observable action of crude animal, plant, and mineral materials occurring in the environment, materials which must have been noted in the continuous search for food, or as a result of accidental contact; (2) no significant poisonous or toxic agents are recommended in the 
old Egyptian medical texts, in spite of the considerable number of such materials which occur naturatly in the Egyptian environment, and which have been described by Lucas, and (3) the various drugs recommended for therapeutic use in the old Egyptian Papyri would seem to tend toward beneficial results, as judged on the basis of modern knowledge. 


\section{Summary}

$A_{\text {careful perusal of the eight available old Egyptian }}$ Medical Papyri cannot fail to result in some degree of astonishment at the relatively high character of medical knowledge possessed by the old Egyptian physicians, in contrast as is usual with the superstitious attitude about sickness on the part of the people. Extensive knowledge and observation both of disease and of effective methods of treatment seem to have been subjected professionally to analysis, classification, and arrangement. The organization of the material indicates wise consideration with resulting logical if unconscious analysis; some of the subject matter seems to have been arranged for professional teaching purposes, as indicated in the Edwin Smith and Ebers Papyri. The basic approach to individual instances of disease in particular patients, by examination, diagnosis, prognosis, and treatment, is fundamentally logical, and is still followed today.

Practicing physicians in old Egypt seem to have had enough professional morale to have obtained special compilations of recommended prescriptions for reference in therapy, as indicated in the Hearst and Berlin Medical Papyri. An important and dominating etiological concept had been developed in regard to pus and suppuration. Handicapped by lack of a technical terminology and by continuous temptation to supernatural rationalizing, the Egyptian physicians on the whole appear to have done better than might have been anticipated in handling their professional affairs. 
On the other hand, the copying of recitals and abjurations into the formularies, and the superstitious character of the Erman document with its charms and magical approach to disease, indicate a popular body of medical belief quite contrary to the rational and empirical professional effort in old Egypt. This dichotomy between the rational, empirical, and essentially scientific approach to disease by professional physicians, and the anxiously confused, irrational, and superstitious attitude about disease on the part of the people generally, persists in the most civilized countries at the present time. Two factors are chiefly responsible for the popular attitude: (1) the tendency for sick people to improve regardless of treatment (vis medicatrix naturae), and (2) the logical fallacy of confusing mere sequence of events with a supposed cause-effect relation. From primitive times these interrelated factors, which were first recognized by the Greeks, have promoted magic, quackery, and cultism in medical matters. It is wise in considering the historical development of medicine and science to differentiate clearly between (1) the professional standards and achievements of physicians and (2) the general current attitude of the people toward disease and its management. 


\section{Appendix:}

\section{List of Prescriptions in the Hearst Medical Papyrus}

The following list of prescriptions in the Hearst Medical Papyrus is numbered serially according to Wreszinski. It gives the full translated title of each prescription. It also notes the sheets of the papyrus, together with the lines in which each prescription appears. Under "Remarks" are indicated the general character of each prescription; whether or not it contains measured quantities of drugs; how it is to be administered; its relation, if any, to other Egyptian papyri, and such special notation as may not be indicated by the character of the prescription.

No. Title $\begin{gathered}\text { Sheet } \\ \text { and line } \\ \text { of papyrus } \quad \text { Remarks }\end{gathered}$

1

2 Doses for purging the body (when the excrements are bound)

3 A prescription (to purge the body)

4 A prescription for expelling the gripping pains of the anus

5 (A prescription ......)

6 Another

7 A prescription for the anus being diseased

8 (A prescription to make firm a tooth which) is about to fall out
I:1 A tablet for oral administration. Contains honey.

I:1-2 Pills made with dough and honey. Semiquantitative. Contains $s^{\prime} s^{\prime}$.

I:2-3 Ebers 32 has same ingredients; Ebers 34 has same heading. Salt and honey for four days. Semiquantitative. Contains salt and beer.

I:3-4 For local application. No amounts of drugs.

I:5 For bandaging for four days.

I:5-6 Gourd meal and honey, amounts not specified. Contains gourds.

I:6 Fumigation with limestone, sand, and dough. Not quantitative.

I:7 Quantitatively devised for local application. Contains dum palm, $s m$, and gum. 


No. Title $\begin{gathered}\text { Sheet } \\ \text { and line } \\ \text { of papyrus } \quad \text { Remarks }\end{gathered}$

9 To cure blood in (the mouth)

10 (A prescription to knit a broken bone) on the first day

11 A second prescription

12 A third prescription

13 To cause a broken bone to knit: in any limb of a male or female

14 To cause to knit

15 Prescription for broken ribs, on the first day

16 Actually to expel "death"

17 To remove scurf from the head

18 A prescription to alleviate (urinating) of much blood

19 A prescription for $w h j$

20 A prescription for allaying rumbling within

21 A prescription made for a bite on human beings

22 A second prescription
I:7-8 Quantitative mouth wash. Similar to Ebers 749. Contains fig-mulberry, and anise.

I:9-10 Semi-quantitative mixture to be bandaged in place for four days. Begins series of flour paste casts.

I:10-11 Flour, cream, and honey cast. No amounts specified. Contains barley.

I:11-12 Similar to Hearst 218. Semiquantitative.

I:12-13 Dough and honey cast to be bandaged in place. No amounts given.

I:13-15 Quantitative mixture to be bandaged in place for four days. Similar to Hearst 221. Contains thistle.

I:15-16 Cream and cloth wrapping for four days. No amounts indicated.

I:16-17 Quantitative mixture for oral adII:1 ministration. Identical with Ebers 182. Contains safflower and terebinth.

II:1-4 A quantitative ointment with detailed directions for use.

II:4-5 Quantitative mixture to be taken by mouth for four days. Similar to Ebers 49. Contains leaven, and oil.

II :5 "Bull's blood" by mouth (for worms?).

II:5-6 "Pig's blood" and wine to be drunk immediately.

II:6-7 For local application. No amounts given. Similar to Ebers 432 and Hearst 240. Contains leek.

II:7 Quantitative mixture to be bandaged in place. Identical with Ebers 433. Contains incense, $s t j$, and bile. 


No. Title $\quad \begin{gathered}\text { Sheet } \\ \text { and line } \\ \text { of papyrus } \quad \text { Remarks }\end{gathered}$

$23 \mathrm{~A}$ third prescription

24 To remove that which moves about on the head

25 A prescription to remove internal ailments

26 A prescription to break up pains within the body

27 A prescription to expel the $h n^{\mathrm{c}} . w$ of the legs

28 A prescription to cure the left side

29 A prescription to break up pains within the body

30 To expel pains in the skin

31 To remove bad odor in summer

32 To expel bad odor from the body

33 To stop illness in the members

34 To expel sickness from all members

35 A prescription to cause an abscess (or swelling) in the pubic region to subside
II:7-8 Quantitative salve. Similar to Ebers 434. Contains garlic.

II:8-9 Quantitative ointment to be rubbed on daily. Similar to Ebers 437.

II:9-10 Semi-quantitative gruel to be swallowed for four days.

II:10-11 Quantitative mixture with beer as the vehicle, to be swallowed for four days. Contains juniper, and yeast.

II:11-12 Quantitative mixture with water as the vehicle, to be swallowed for four days.

II:12-14 Quantitative c o m p lex mixture with water as the vehicle, to be swallowed for four days. Similar to Ebers 631 and 632. Example of polypharmacy.

II $14-15$ Quantitative mixture with beer as the vehicle, to be swallowed for four days. Similar to Hearst 26 and Ebers 97.

II:15-17 Quantitative mixture with milk and beer as the vehicle, to be given "as above."

II:17 Quantitative ointment, similar to Ebers 708 and Hearst 150. Con-

III:1 tains myrrh.

III:1-2 Frankincense made into pills with dough to be put "where limb joins with limb." Similar to Ebers 711 and Hearst 151. No amounts given.

III:2-3 A dough poultice, similar to Ebers 301. Not quantitative.

III:3-4 A quantitative ointment. Contains acacia.

III:4-6 Part of an herb to be rubbed on. Similar to Ebers 294. 


No. Title $\begin{gathered}\text { Sheet } \\ \text { and line } \\ \text { of papyrus } \quad \text { Remarks }\end{gathered}$

36 To drive out a "seizure" III:6-7 from the body

37 Applications for jumping in the limbs

38 A prescription for scy.t

39 To alleviate burns

40 Another prescription

41 A prescription to remove throbbing pains in any limb of a patient

42 A prescription to deaden pains in any limb

43 Another

44 Another

45 Another

46 Doses for killing pains in any limb

47 A prescription to kill the pains in the body

48 A prescription for removing sickness of the stomach

49 Another prescription

50 A prescription for causing the stomach to receive food
Date stones, frankincense, and juniper berries to be swallowed. Similar to Ebers 165 and Hearst 54. No amounts specified.

III:7-8 A non-quantitative myrrh poultice.

III:8 Another non-quantitative poultice.

III:8-9 Unspecified amounts of gourd seeds, salt, and urine for local application. Identical with Ebers 537.

III:9-10 A non-quantitative mucilaginous poultice to be applied with a bandage. Similar to Ebers 538 . Contains natron (soda).

III:10-11 Excrements and $h t-w \dot{s}$ bandaged on. Identical with Ebers 584. No amounts given.

III:11-13 Complex quantitative mixture to be swallowed for four days. Similar to Berlin 161. Vehicle is d's.t beverage and beer. For diuresis?

III:13-14 Vehicle is beer.

III:14-15 Vehicle is wine. Contains dill.

III:15-17 Vehicle is juice of the gourd.

III:17 Similar to preceding group. Water is the vehicle.

IV:1-2 Similar to the preceding group. Vehicle is milk.

IV:2-3 Quantitative mixture with beer as the vehicle to be swallowed for four days. Identical with Ebers 217.

IV:3 Quantitative milk, honey, and water preparation to be swallowed for four days. Identical with Ebers 218.

IV:4 Quantitative carminative, chalk, and honey mixture "as above." 
Sheet

and line

No. Title

of papyrus

Remarks

51 A prescription for curing the heart

52 Another

53 A prescription to remove sickness from the body

54 A prescription to drive out a "spell" from the body

55 A prescription regarding the body when it is sick

56 Another

IV:8

57 An immediate remedy for the cure of the lung

58 Doses to purge the body

59 A prescription for causing one to urinate

60 Another

61 A prescription to get rid of nausea

62 An immediate treatment for the urinating organ, (and) to correct the urine
IV:4-5 Quantitative gruel preparation to be swallowed for four days, probably for "heartburn" (gastric acidity).

IV:5-6 Quantitative mixture with milk, and water as the vehicle, to be administered "as above."

IV:6 Peas and beer to be swallowed. No amounts noted. Similar to Ebers 4.

IV:6-7 Quantitative mixture to be washed down with beer. Similar to Ebers 165 and Hearst 36.

IV:7-8 Quantitative mixture of cumin, goose fat, and milk to be given "as above." Identical with Ebers 5.

Quantitative mixture of fruit and beer, to be given "as above." Identical with Ebers 6.

IV:8-9 Quantitative mixture with water as a vehicle, to be swallowed for four days.

IV:9-10 Quantitative milk, fig-mulberry, and honey mixture to be swallowed for four days. Identical with Ebers 7.

IV:10-11 Semi-quantitative mixture with beer as the vehicle, to be swallowed for four days. Similar to Ebers 9.

IV:11 Semi-quantitative mixture with beer as the vehicle, "to be swallowed."

IV:11-12 Quantitative mixture with milk as a vehicle, to be swallowed for four days.

IV:12-14 Quantitative mixture with beer as the vehicle, to be swallowed for four days. Similar to Ebers 271. Contains cassia, and cucumber. 
Sheet

and line

No. Title of papyrus

Remarks

63 Doses to alleviate excessive urine

64 Another

65 Another

66 Another

67 To correct the urine

68 A prescription for the urine being held back

$\mathrm{V}: 2-4$

69 To cure the sending forth of heat from the bladder

70 To expel the sending forth of heat from the bladder

71 A second prescription which Shu made for $\left(\operatorname{Re}^{\mathrm{c}}\right)$ himself

72 A third prescription which Tefenet made for $R \hat{e}^{c}$ himself

73 A fourth prescription made by Geb for $\left(\mathrm{Re} \hat{e}^{\mathrm{c}}\right)$ himself

74 A fifth prescription made by Nut for $R \hat{e}^{c}$ himself
IV:14-15 Quantitative mixture with water as the vehicle, to be given "as above." Similar to Ebers 277.

IV:15-16 Quantitative mixture with beer as the vehicle, to be "swallowed for one day." Identical with Ebers 278.

IV:16 Quantitative preparation of gum, honey, and water, to be "swallowed for one day." Similar to Ebers 280.

IV:16 Quantitative mixture with water V:I as the vehicle, to be given "as above." Identical with Ebers 279.

V:1-2 Quantitative mixture with beer as the vehicle, to be swallowed for four days. Similar to Ebers 278 and to Hearst 64.

Quantitative mixture to be swallowed for four days. Similar to Ebers 282.

V:4-5 Quantitative mixture with water as the vehicle, to be swallowed for four days.

V:5-7 Quantitative mixture of ingredients with water as the vehicle, to be swallowed for four days.

V:7-9 Mixture of 5 ro each of eleven ingredients for single application by bandage to the affected part. Identical with Ebers 243. Contains soot.

$\mathrm{V}: 9-10$ Mixture in 5 ro amounts of flour and oil for single application by bandage. Similar to Ebers 244.

$\mathrm{V}: 11-12$ Mixture in 5 ro amounts of powdered seeds, and yeast for single application by bandage. Similar to Ebers 245.

$\mathrm{V}: 12-15$ Mixture of 5 ro quantities of chiefly mineral and oil ingredients, for single application by bandage. Similar to Ebers 246. 


No. Title $\begin{gathered}\text { Sheet } \\ \text { and line } \\ \text { of papyrus } \quad \text { Remarks }\end{gathered}$

75 A sixth prescription which Isis made for $\mathrm{Re}^{\mathrm{c}}$ himself: in order to expel pains in his head

76 A prescription to expel ills in the head or complaints in the head

77 Another prescription

78 A recital during the application of a remedy to any limb, which is diseased.

79 To expel fluid accumulations from the body (and) from the heart

80 A prescription to expel fluid accumulations from the body (and) from the heart

81 Another prescription to expel fluid accumulations from the body (and) from the heart

82 Another prescription

83 To expel the fluid accumulations of a god (or) of an evil thing from the body of a man or woman

84 Another prescription

85a Another prescription
VII $: 2-4$

VI:16-17 Quantitative complex mixture of VII:1-2 plant and mineral remedies, with honey, and dough, to be taken orally for four days. Similar to Ebers 225. Contains stibnite.

VI:14-15 Quantitative plant mixture with honey to be "swallowed before sleeping." Identical with Ebers 223.

VI:15-16 Quantitative mixture of plant drugs with water, for single oral administration. Similar to Ebers 224. Contains lotus.

Quantitative complex mixture of plant and mineral ingredients with honey, and water, to be taken orally for four days. Similar to Ebers 226.

VII $: 4$

V:15-16 Mixture of 5 ro amounts of five plant ingredients with honey for with assurance of value. Like Ebers 247.

VI:2-4 Mixture of 5 ro quantities of plants, salt, fish, and honey, for anointing head for four days. Identical with Ebers 248. and fat, for anointing head for four days. Like Ebers 249.

mixture in honey, to be "swallowed before sleeping." Identical with Ebers 221. Refers to ascites?

VI:12-14 Identical with Ebers 222. Quantitative plant, mineral, and honey mixture to be "swallowed before sleeping."

Abydos fish to be eaten on retiring. 
Sheet

No. Title $\begin{gathered}\text { and line } \\ \text { of papyrus Remarks }\end{gathered}$

$85 \mathrm{~b}$ There is to be said with it as an incantation

86 Another prescription

87 Another prescription

88 A prescription for the perineum when it is sick

89 A prescription for contusions on the first day

90 Another

91 Another

92 Another

93 A prescription to cool the anus

94 The beginning of the treatise for alleviating any disease. A prescription to ease the mt.w.

95 To cool the mt.w

96 A prescription to give relief to the $m t . w$

97 Another

98 Another
VII:5-6 To drive out evil spirits.

VII:7-9 Quantitative complex mixture of mineral and plant remedies, with honey, to be "swallowed before sleeping." Similar to Berlin 115.

VII:9-10 Quantitative mixture of plant remedies in beer, to be taken on retiring. Similar to Ebers 238.

VII:10 Quantitative mixture of palm fruit, and gum in water, to be "swallowed daily."

VII:10-11 Lime, gourds, and bread crumbs, to be applied locally.

VII:11-12 Salt applied locally.

VII:12 Rushes applied locally.

VII:12 Rags applied locally.

VII:12-13 Quantitative mixture of plant remedies in water to be taken orally for four days.

VII:14-16 Complex quantitative mixture of grease, plant materials, frankincense, and myrrh, for local application. Similar to Ebers 657 and Hearst 237.

VII:16 Quantitative mixture of plant inVIII:1 gredients with salt, to be applied locally with bandage. Similar to Hearst 238. Contains willow.

VIII:1-2 Quantitative ointment of oil and resin. Similar to Ebers 627 .

VIII:2 Quantitative mixture of leather and plant kernels applied presumably by rubbing. Identical with Ebers 628 .

VIII:2-3 Quantitative astringent, oil, and honey mixture applied by inunction after myrrh. Related to Ebers 629. 
Sheet

and line

No. Title

of papyrus

Remarks

99 A preparation for a $m t$ which throbs in any limb

100 To give relief to the interior of a $m t$

101 To enliven and freshen a $m t$

102 A prescription to give relief to a $m t$

103 Another

104 To quiet the mt.w

105 Another

106 Another

107 Another

108 Another

109 Another

110 A preparation for a $m t$ which becomes stiff

111 To cause a $m t$ to receive medicine

112 Another
VIII:3-4 Quantitative plant and honey preparation applied by inunction. Similar to Ebers 644. Contains twn.

VIII:4-5 Quantitative plant, salt, and bread crumb preparation to be applied locally.

VIII:5-6 Myrrh, frankincense, and resinous mixture to be applied by bandage after inunction with myrrh. Similar to Ebers 652 .

VIII:6-7 Quantitative resinous preparation for application by bandage.

VIII:7 Quantitative mixture of plant materials, resin, and honey, to be applied by bandage.

VIII:7-8 Mixture of resins, oil, minerals, and honey, to be applied by bandage. Similar to Hearst 229 and related to Ebers 687.

VIII:8 Pasty mixture to be applied by bandage.

VIII:8-9 A mixture for application by bandage.

VIII:9-10 Complex waxy mixture to be applied by bandage after rubbing with myrrh. Similar to Ebers 649 and Hearst 228.

VIII:10 Spicy mineral mixture with honey, to be applied by bandage. Similar to Hearst 230.

VIII:10-11 Aromatic astringent paste to be applied by bandage.

VIII:11-12 Ground mint and pondweed applied by bandage. Identical with Ebers 694.

VIII:12-13 Soapy preparation to be applied by rubbing. Similar to Ebers $6+2$.

VIII:13 Yeast and beer mixture applied by rubbing. Identical with Ebers 643. 


No. Title $\begin{gathered}\text { Sheet } \\ \text { and line } \\ \text { of papyrus } \quad \text { Remarks }\end{gathered}$

126 Another

127 A prescription to drive away swellings in any member

128 Another

129 A prescription to expel the IX:8-9 "devouring of blood" in any member

130 Another

131 A prescription to drive away bitterness

132 A prescription to open up anything that "gathers" spontaneously

133 To bring water from a boil in any limb of man or woman

134 To expel sores of any member of a man or woman

135

136 To expel swellings

137 To expel swellings

138 To expel obstinate swellings and to stop pains in any limb of a person

139 To drive out swellings
IX:5-6 Quantitative saline astringent

mixture for bandaging. Identical with Ebers 564. Contains charcoal.

IX:6-7 Plant mixture for bandaging. Similar to Ebers 566.

IX:7-8 Saline mixture for bandaging. Similar to Ebers 567, which is quantitative.

Garlic and fat for local application. Similar to Ebers 724.

IX:9 Alkaline leaven for local application. Identical with Ebers 725 .

IX:9-10 Gourds, honey, and beer for oral administration. Similar to Ebers 302.

IX:10-11 Salt and honey mixture for application for bandaging. Similar to Ebers 581 and 588.

IX:11-12 Ground juniper berries for bandaging. Related to Ebers 565, 567, and 569 .

IX:12-13 Preparation of thistle seeds for bandaging.

IX:13 Plant, gum, and salt mixture for bandaging.

IX:13-14 Quantitative plant and salt ointment for bandaging. Related to the Ebers group 556-591.

IX:14-15 Plant ointment applied by bandage for four days.

IX:15-16 Quantitative mixture of acacia seeds and cedar dust for repeated application by bandaging.

IX:16-17 Saline astringent poultice for bandaging. 
Sheet

and line

No. Title

of papyrus

Remarks

140 To expel sicknesses of the blood in any limb of a man or woman; another prescription to bring forth pus

141 Another prescription

142 To cause anything to be active

143 A prescription to expel a pool of blood when it is not yet clotted

144 A prescription to cause hair to grow

145 Another prescription to cause hair to grow

146 Another prescription

147 A prescription to prevent white hair

148 Another

149 Another

150 To expel the bad odor from the body of people in summer time

151 To drive out bad odor in the presence of a man or woman

152 A prescription to purge the body

153 To improve the skin
IX:17-18 Quantitative alkaline astringent

$\mathrm{X}: 1 \quad$ poultice for bandaging. Similar to Ebers 557.

X:1 Quantitative astringent poultice. Similar to Ebers 558 .

X:1-2 Quantitative oily mixture to be taken orally for four days. Identical with Ebers 695.

X:2-4 Quantitative plant mixture with goose fat to be given by mouth for four days. Similar to Ebers 593.

$\mathrm{X}: 4-5 \quad$ Worm, clay, and oil ointment.

$\mathrm{X}: 5-6 \quad$ Ergot, oil, and honey mixture for local application.

X:6-7 Animal fat mixture for inunction. Similar to Ebers 465 .

$X: 7-9 \quad$ Specially prepared plant ointment.

$\mathrm{X}: 9-10$ Rotten liver with oil for inunction. Similar to Ebers 463.

$\mathrm{X}: 10-11$ Rotten mouse in oil for inunction.

$\mathrm{X}: 11-12$ Aromatic ointment. Similar to Ebers 708.

X:12-13 Aromatic pills for local application for four days. Similar to Ebers 711 and Hearst 32.

$\mathrm{X}: 14-15$ Quantitative mixture of plant remedies with milk and honey, to be administered orally for four days. Identical with Ebers 713.

X:14-15 Saline and honey preparation for inunction. Identical with Ebers 714 and with a prescription on the verso of the Edwin Smith Surgical Papyrus. 


No. Title $\begin{gathered}\text { Sheet } \\ \text { and line } \\ \text { of papyrus } \quad \text { Remarks }\end{gathered}$

154 To beautify the color of the skin

155 A prescription to remove hair from any part of the body

156 Another

157 A prescription for baldness

$\mathrm{X}: 16-18$ Gummy mixture to be applied locally.

$\mathrm{X}: 18$ Greyhound blood to be applied locally.

$\mathrm{X}: 18 \quad$ Worm in oil to be applied locally. XI:1 Similar to Ebers 474.

158 Another

XI:1 Lotus leaf in oil to be applied locally. Similar to Ebers 475 .

$159 \mathrm{a}$ To expel bewitchment

XI:1-2 Beetle in oil to be applied locally. Similar to first part of Ebers 733.

$159 \mathrm{~b}$ If afterwards you wish to drive it out

$\mathrm{XI}: 2-3$ Beetle parts in worm grease to be administered orally. Similar to the latter part of Ebers 733.

160 Adjuration against the $m s$ pn.t disease

XI:3-6 Incantation for herbs to be applied locally.

XI:6-7 Myrrh and coriander mixture to be applied locally.

162 Another

XI:7 Alkaline ointment for local application.

163 Another

XI:7 Sunflower roots applied locally.

164 Another

$\mathrm{XI}: 7-8$ Alkaline ointment for bandaging.

165 Another

XI:8 Hippopotamus fat applied locally.

166 Another

XI:8-9 Alkaline ointment applied locally.

167 To expel $m s^{x} s w . t$

XI:9-10 Ointment of snake skins, cream, and cinnamon fruit.

168 A prescription to expel tm j.t

XI:10-11 Alkaline adsorbent mixture for application with bandage.

169 Another
XI:11-12 Mixture of plant ingredients with honey, for application with bandage. 


\begin{tabular}{|c|c|}
\hline No. & Title \\
\hline 170 & $\begin{array}{l}\text { Adjuration against } \\
\text { the Asiatic disease }\end{array}$ \\
\hline 171 & $\begin{array}{l}\text { A prescription to } \\
\text { cure the irwtn disease }\end{array}$ \\
\hline 172 & $\begin{array}{l}\text { Another (against) } \\
\text { śspn sickness }\end{array}$ \\
\hline $173 a$ & $\begin{array}{l}\text { a A prescription to cure } \\
\text { a finger or toe }\end{array}$ \\
\hline \multicolumn{2}{|c|}{$\begin{array}{l}\text { 173b Afterwards make for } \\
\text { him a prescription }\end{array}$} \\
\hline & $\begin{array}{l}\text { If you find finger or } \\
\text { toe diseased, with fluid } \\
\text { gathered within it, with } \\
\text { bad odor, (and) resulting } \\
\text { in } s^{\prime} \text { worms }\end{array}$ \\
\hline
\end{tabular}

175a To cure a sick toe

$175 \mathrm{~b}$ After you have made this mixture

176 Another prescription

177 A prescription for a toenail

178 Another prescription

179 A prescription to cure a toenail which is falling off

180 An application for the toe
Sheet

and line

of papyrus

XI:12-15 Incantation for olive oil and kettle scales.

XI:15-16 Mint (?) in wine to be drunk. Bloodletting is suggested.

XI:16-17 Mint (?) rubbed on the nose.

XI:17-18 Alkaline honey mixture for bandaging. Similar to first part of Ebers 616 .

XI:18 Quantitative plant and mineral XII:1 preparation applied by bandaging. Identical with second part of Ebers 616.

XII:1-3 Quantitative mineral and oil mixture applied by bandaging. Implied examination and diagnosis. Identical with Ebers 617 .

XII:3-4 Mineral mixture for application by bandaging. Similar to first part of Ebers 620 .

XII:4-5 Grease, oil, and honey ointment applied locally. Identical with second part of Ebers 620 .

XII:5-6 Frankincense, oil, and honey applied locally.

XII:6-7 Quantitative plant and mineral mixture applied by bandaging. Similar to Ebers 618 and Hearst 188.

XII:7 Quantitative mixture of honey, mineral, and oil applied locally. Identical with Ebers 619 and Hearst 189.

XII:7-8 Mixture of minerals, frankincense, oil, and honey, to be applied locally with light bandaging. Similar to Ebers 622 , which is quantitative.

XII 9 Grease and acacia buds applied locally. 


\begin{tabular}{lll} 
No. Title & $\begin{array}{c}\text { Sheet } \\
\text { and line } \\
\text { of papyrus }\end{array}$ & \multicolumn{1}{c}{ Remarks } \\
\hline 181 A prescription (and) & XII:9 & $\begin{array}{l}\text { Plant and oil preparation applied } \\
\text { by bandage. }\end{array}$ \\
$\begin{array}{l}\text { application for the finger } \\
182 \text { A prescription to } \\
\begin{array}{l}\text { drive away blood } \\
\text { from the toe }\end{array}\end{array}$ & XII:9-10 & $\begin{array}{l}\text { Ground acacia rind (?) applied } \\
\text { by bandage. }\end{array}$
\end{tabular}

183 Another prescription

XII:10-11 Frankincense ointment to be applied by bandage.

184a An application for toenails, which on account of sores are "openmouthed"

$184 \mathrm{~b}$ Afterwards you shall make for him

XII:12 Astringent ointment to be applied by bandage.

185 To cure the nails of toe (or) finger

186 Another prescription

187 Another prescription

188 A prescription for the nail of a toe

XII:11-12 Plant and saline preparation to be applied by bandage.

XII:13-14 Saline astringent ointment for application with bandage.

XII:14 Frankincense and mineral ointment to be applied with bandage.

XII:15 Mild astringent poultice to be applied by bandage. Contains flax.

XII:15-16 Quantitative plant and mineral mixture applied by bandaging. Similar to Ebers 618 and Hearst 177.

189 Another prescription

XII:16-17 Quantitative oil and mineral preparation for application by bandage. Similar to Ebers 619 and Hearst 178.

190 Another prescription

XII:17 Quantitative honey and mineral preparation for application by bandage.

191 Another

XII:17 Complex quantitative plant and XIII:1 mineral preparation for application by bandage.

192 Another prescription

XIII:1-2 Quantitative plant and mineral mixture but lacks directions for use.

193 To cure the nails of

XIII:2-3 Mineral preparation with honey a toe and oil, to be applied by bandage. Similar to Ebers 621 , Hearst 173 , and the first part of Ebers 616. 
Sheet

and line

No. Title

of papyrus

Remarks

194 A prescription for fingers and toes: To

XIII:3-4 Ointment of vegetable and resin refresh the fingers: A preparation for the nail

195 To cure the toe

XIII:4 Plant material in oil to be applied by bandage.

196 To remove maggoty flesh XII:5 from finger (and) toe

197 A prescription for the toe

XIII:5-6 Worm and salt applied by bandage.

198 Another prescription

XIII:6 Animal brain (?) in oil, applied by bandage.

199 A prescription for drying moisture in the toenails

200 To expel swellings from a toe

Plant and mineral mixture to be applied by bandage.

201 Another prescription

202 Another prescription

203 Another prescription

204 To remove warts (?) on a finger

XIII:6-7 Peas, gourd seeds, and honey applied with bandage.

XIII:7-8 twn fruit with honey, applied by bandage.

XIII:8-9 Plant materials "bound" with honey and applied by bandage.

XIII:9-10 Plant and mineral material with honey, applied by bandage.

XIII:10 Shad brain (?) with honey, applied by bandage. Similar to Ebers 128.

XIII:10-11 Mixture of plant materials with salt and honey, to be applied with bandage.

205 A prescription to get rid of trembling in the fingers

XIII:11-12 Rub with oil and bandage with melons. Related to Ebers 623 and 624.

206 A prescription for nśj.t

XIII:12-13 Quantitative plant mixture for oral administration. Similar to Ebers 752.

207 Another prescription

XIII:13-14 Quantitative plant preparation in oil, honey, and beer, to be taken orally for four days. Similar to Ebers 754.

208 Another prescription

XIII:14-15 Powdered dung in winc given orally for one day. Similar to Ebers 756. 


No. Title $\begin{gathered}\text { Sheet } \\ \text { and line } \\ \text { of papyrus }\end{gathered}$ Remarks

209 Another prescription

210 Another

211 To expel nśj.t

212 The recital for the measuring utensil on taking it in order to measure a prescription

213 The recital for the bushel measure

214 The recital for the oil of every prescription

215 The recital for the honey

216 The recital for the beer

217 A prescription to knit a broken bone, on the first day

218 A second prescription

219 A third prescription

220 Another prescription

221 Another prescription

222 Another prescription
XIII:15-16 Plant materials in beer administered orally. Similar to Ebers 751.

XIII:16 Salt and dough to be taken by mouth. Similar to Ebers 753 .

XIII:16-17 Plant materials in beer to be swallowed.

XIII:17 Reminder for care when using XIV:1-2 measuring utensil.

XIV:2-4 Suggests accuracy of measure.

XIV:4-7 Supplication for efficacy of oil.

XIV:7-10 Supplication for efficacy of honey.

XIV:10-13 Ritual including "stage directions," for inspiring confidence in the beer to be used.

XIV:13-14 Quantitative flour paste cast to be applied with bandage for four days. Similar to Hearst 10.

XIV:14-15 Quantitative flour paste to be applied by bandage. Similar to Hearst 12.

XIV:15-16 Quantitative cream and flour paste to be applied with bandage for four days. Similar to Hearst 11.

XIV:16-17 Quantitative honey and dough mixture to be applied with bandage for four days. Related to Hearst 13.

XIV:17 Quantitative mixture of plant $X V: 1$ buds, honey, and gum for application with bandage. Similar to Hearst 14.

XV:1-2 Quantitative plant and honey paste to be applied with bandage for four days. 


No. Title $\begin{gathered}\text { Sheet } \\ \text { and line } \\ \text { of papyrus } \quad \text { Remarks }\end{gathered}$

223 Another prescription

224 Another prescription

225 Another prescription

226 A prescription for "cooling" the bone after it is set in any member of the body of a patient

227 Another prescription

228 A prescription to soothe the mt.w in any limb of a patient

229 Another prescription

230 Another prescription for soothing the $m t . w$ in any limb of a patient

231 Another prescription

232 A prescription to relax the mt.w in any limb of a man or woman

233 A prescription for "cooling" a bone after it is set in any limb of a patient

234 Another prescription

235 Another prescription to expel swellings in any limb of a patient
$X V: 2$ Quantitative paste for cast of acacia and gum to be used with bandage for four days.

$\mathrm{XV}: 3$ Quantitative mixture of gum, fat, and wax, to be applied with bandage for four days.

XV:3-4 Oily worm to be applied by bandage.

XV:4-5 Quantitative plant poultice to be applied with bandage. Three of five plant ingredients are buds.

XV:5-6 Complex quantitative oil and mineral mixture to be applied with bandage for four days.

$\mathrm{XV}: 6-8$ Complex quantitative fat and plant mixture to be applied with bandage, after rubbing with myrrh. Similar to Ebers 649.

XV:8-10 Quantitative complex plant and mineral antiseptic preparation for application by bandage.

XV:10 Quantitative alkali, spice, and honey mixture for application by bandage. Similar to Hearst 108.

$\mathrm{XV}: 10-11$ Quantitative spice and mineral ointment to be applied by bandage for four days. Similar to Hearst 109.

XV:11-13 Quantitative mineral and spice ointment to be applied by bandage for four days.

$\mathrm{XV}: 13-14$ Alkaline honey cast for application by bandage for four days. Similar to Ebers 636 .

XV:14-15 Gummy cast to be applied by bandage for four days.

$\mathrm{XV}: 15-16$ Quantitative spice ointment to be applied by bandage for four days. Same heading as Hearst 127. 
Sheet

and line

No. Title

of papyrus

Remarks

236 Another prescription to expel swellings

237 Another prescription to sooth the mt.w

238 Another prescription to cool the $m t . w$ in any limb

239 Another prescription for the bite of a crocodile on any limb of a person

240 Another prescription

241 Another prescription for the bite of a pig

242 Another prescription

243 (Another prescription for) the bite of a hippopotamus

244 (Another prescription for) the bite of a lion

245 A prescription for (the healing of) wounds in any limb

246 Another prescription for (.........)

247 (Another prescription for ........)

248 (Another prescription for ........)

249 (Another prescription) to soothe the $m t . w$
$X V: 16-17$ Quantitative plant and mineral XVI:1 mixture for application by bandage.

XVI:2 Quantitative plant, spice, and mineral ointment to be applied by bandage. Similar to Hearst 94 and Ebers 657.

XVI:2-4 Quantitative plant and salt mixture to be applied by bandage for four days. Similar to Hearst 95.

XVI:4-5 Meat bandage on first day. Similar to Ebers 436 .

XVI:5 Jar scrapings and leek to be applied by bandage for four days.

XVI:5-6 Meat bandage for first day. Similar to Hearst 239.

XVI:6-7 Incomplete quantitative mineral and plant ointment to be applied by bandage.

XVI:7-8 Incomplete mulberry and beer mixture for application by bandage.

XVI:8-9 Incomplete plant mixture applied with bandage for four days.

XVI:9-10 Incomplete quantitative ointment to be applied by bandage.

XVI:10-11 Incomplete quantitative alkali and wine mixture to be applied by bandage for four days.

XVI:11-12 Incomplete quantitative mixture to be applied by bandage for four days.

XVI:12-13 Incomplete quantitative honey mixture to be applied by bandage for four days.

XVI:13-14 Incomplete quantitative mixture to be applied by bandage. 
Sheet

and line

No. Title of papyrus

Remarks

250 Another prescription

XVI:14-17 Incomplete complex quantitative plant and mineral mixture to be applied by bandage.

251 Another prescription to $\mathrm{cool}$

XVI:17 Incomplete plant and salt ointXVII:1-3 ment.

252 (A prescription for healing) the knee

XVII:3-4 Incomplete herb preparation. when it is injured

253 (Another) to expel "heat"

XVII:4-5 Incomplete preparation for application by bandage.

254 Another (prescription)

XVII:5-6 Incomplete preparation to be heated and applied locally.

255 (Another)

XVII:6-9 Incomplete salt and acacia mixture to be applied by bandage on the inflamed part.

256

XVII:9-10 Nothing except directions for application by rubbing.

257 Another

XVII:10-12 Incomplete plant preparation. Probably applied with wool rag.

258 A prescription (for) ...... XVII:12-14 Incomplete oil and sulphur preparation applied locally.

259 Another

XVII:14-16 Incomplete salt, spice, and plant mixture.

$260 \ldots . . . . . . . w o u n d$ in any limb

XVII:16 Incomplete spicy poultice XVIII:1-2 applied locally. 


\section{References}

Adams, F., The Seven Books of Paulus Aegineta: Translation with Commentary, London, Sydenham Soc., 1847, 3 vols.

Albright, W. F., "The Role of the Canaanites in the History of Civilization," Studies in the History of Culture, Conference of Secretaries of the American Council of Learned Societies, Menasha, Wisconsin, 1942, pp. 11-50.

Breasted, J. H., A History of Egypt from the Earliest Times to the Persian Conquest, New York, Chas. Scribner's Sons, 1905, xxxix +634 pp.

- Ancient Records of Egypt: Historical Documents from the Earliest Times to the Persian Conquest, University of Chicago Press, 1906, 4 vols., xviii +2500 pp.

- The Edwin Smith Surgical Papyrus: Facsimile and Hieroglyphic Transliteration with Translation and Commentary, 2 vols., University of Chicago Press, 1930.

Budge, E. A. W., The Dwellers on the Nile: Chapters on the Life, History, Religion and Literature of the Ancient Egyptians, London, Relig. Tract. Soc., 1926, xxxii + 326 pp.

Champollion, J. F., Précis du Système Hiéroglyphique, Paris, 1824; Analyse Méthodique du Texte Démotique de Rosette: Aperçu des Resultats Historiques de la Decouverte de l'Alphabet Hiéroglyphique, Paris, 1827.

Clendening, L., Source Book of Medical History, New York, P. B. Hoeber, 1942, 702 pp.

Cuppy, W., The Decline and Fall of Practically Everybody, Holt, New York, 1950, 230 pp.

Dawson, W. R., "The Mouse in Egyptian and Later Medicine," J. Egypt. Arch., 10: 83-86, 1924.

- "The Plant Called 'Hairs of the Earth," " J. Egypt. Arch., 12: 240-241, 1926.

, "Three Anatomical Terms (from Old Egypt)," Ztschr. Ägypt. Spr., 62: 20-23, 1927.

, Clio Medica: The Beginnings: Egypt and Assyria, New York, P. B. Hoeber, 1930, 86 pp.

- "Studies in the Egyptian Medical Texts," I. Egypt. Arch., 18: 150-154, 1932; 19: 133-137, 1933; 20: 41-46, 185-188, 1934; 21: 37-40, 1935.

DeLint, J. G., "Beiträge zur Kenntnis der Anatomischen Namen im Älten Ägypten," Arch. Gesch. Med., 25: 382-390, 1932. 
Ebbell, B., "Die Ägyptischen Krankheitsnamen," Ztschr. Ägypt. Spr., 59: 55-59, 144-149, 1924; 62: 13-20, 1927; 63: 71-75, 115121, 1928; 64: 117-122, 1929.

—_ "Die Ägyptischen Drogennamen," Ztschr. Ägypt. Spr., 64: 48-54, 1929.

Orient., 10: 95-107, 1932.

- The Papyrus Ebers: The Greatest Egyptian Medical Document, Levin \& Munksgaard, Copenhagen, 1937, 135 pp.

Ebers, G., Papyros Ebers: Das Hermetische Buch über die Arzneimittel der Alten Aegypter, Leipzig, J. C. Hinrichs, 1875, 2 vols. Eid, A., Histoire de la Médicine en Egypt, Cairo, Imprimerie Nat., 1904, 50 pp.

Eisenlohr, A., Ein Mathematisches Handbuck zu Alten Aegypter. (Papyrus Rhind des British Museum), Leipzig, J. C. Hinrichs, 1877.

Erman, A., The Literature of the Ancient Egyptians: Poems, Narratives and Manuals of Instruction, trans. by A. M. Blackman, London, Methuen, 1927, xvii+318 pp.

- "Zaubersprüche für Mutter und Kind: Aus dem Papyrus 3027 des Berliner Museums," Abhdl. kgl. Preuss. Akad. Wiss., Berlin, 1901.

Evans, H. M., Exhibition of First Editions of Epochal Achievements in the History of Science, Berkeley, University of California Press, 1934, 48 pp.

Fulton, J. F., Logan Clendening Lectures on the History and Philosophy of Medicine, First Series: I. Vesalius Four Centuries Later, II. Medicine in the Eighteenth Century, University of Kansas Press, Lawrence, 1950, 52 pp.

Glanville, S. R. K., The Legacy of Egypt, Oxford, Clarendon Press, 1942, xx+424 pp.

Grapow, H., Untersuchungen über die Altägyptischen Medizinischen Papyri, Teil 1 (Mitteilungen der Vorderasiatisch-Aegyptischen Gesellschaft, 40 Band, 1 Heft), 1935, J. C. Hinrichs, Leipzig, $111 \mathrm{pp}$.

- "Bemerkungen zum Papyrus Ebers als Handschrift," Ztschr. Aegypt. Spr., 71: 160-164, 1935.

, Über die Anatomischen Kenntnisse du Altägyptischen Ärte, Leipzig, J. C. Hinrichs, 1935, 30 pp. +9 pl. Hieroglyphic Text.

- "Die Ägyptischen Medizinischen Papyri und Was Sie Enthalten," Münch. Med. Wchnschr., 82: 958-962; 1002-1005, 1935. 
Untersuchungen uber die Altägyptischen Medizinischen Papyri, II Teil (Mitteil. Vorderasia-Aegypt. Gesellsch. $41 \mathrm{Bd}$., Heft 2), J. C. Hinrichs, Leipzig, 1936, 138 pp.

Griffith, F. Ll., "The Metrology of the Medical Papyrus Ebers," Proc. Soc. Bibl. Arch., 13: 392-406, 1891; with Appendix I, "The Figures and Symbols of the Berlin Medical Papyrus," ibid., pp. 526-528;

Appendix II, "The Unit of the Integral Series: + the Cubic Quarter: Conclusions,” ibid., pp. 528-530;

Appendix III, "The Symbols in Hieroglyphics: The Subdivisions of the Apt at Medinet Habn: The one ro or 'part', a Greatest Common Measure," ibid., pp. 530-538; "Table of Figures and Symbols," pp. 536-538.

- "The Rhind Mathematical Papyrus," Proc. Soc. Bibl. Arch., 13: 328-332, 1891.

- The Petrie Papyri: Hieratic Papyri from Kahun and Gurob (Principally of the Middle Kingdom), London, B. Quaritch., 1898, vi + 114 pp.

- "Ancient Egypt: Egyptian Language and Writing," Encyclopedia Britannica, 11th Ed., Cambridge, 1911, Vol. IX, 57-65.

Gunther, R. T., The Greek Herbal of Dioscorides, Oxford University Press, 1934, $701 \mathrm{pp}$.

Hayes, W. C., and H. M. Herget, "Daily Life in Ancient Egypt," Nat. Geog. Mag., 80: 419-515, 1941.

Hurry, J. B., Imhotep the Vizier and Physician of King Zozer and Afterwards the Egyptian God of Medicine, Oxford Univ. Press, 2nd Ed., 1928.

Jonckheere, F., Le Papyrus Medical Chester Beatty, Brussels, 1947.

Leake, C. D., "Ancient Egyptian Therapeutics," Ciba Symp., 10: 311-322, 1940.

Leigh, R. W., "Notes on the Somatology and Pathology of Ancient Egypt," Univ. California Publ. Arch. Eth., 34: 1-37, 1934.

Loret, V., La Flore Pharaonique, Paris, E. Leroux, 2nd Ed., 1892, $145 \mathrm{pp}$.

Lucas, A., "Cosmetics, Perfumes and Incense in Ancient Egypt," J. Egypt. Arch., 16: 41-53, 1930.

-"The Occurrence of Natron in Ancient Egypt," J. Egypt. Arch., 18: 62-66, 1932. 1938.

Lutz, H. E., "A Remark on Egyptian $r$ part," J. Amer. Orient. Soc., 40: 359-361, 1920. 
"Speech Consciousness among Egyptians and Babylonians," Osiris, 2: 1-27, 1936.

Manascha, I., "Die Geburtshilfe bei den Alten Aegyptern," Arch. Gynäkol., 131: 425-461, 1927.

Möller, G., "Die Zeichen fur die Bruchteile des Hoklmasses und das Uzatange," Ztschr. Aoegypt. Spr., 48:99-101, 1911.

, Hieratisch Paläographie: Die Aegyptische Buchschrift in Ihrer Entwicklung von der Funften Dynastie bis zur Romischen Kaizerzeit, 2nd Ed. Leipzig, J. C. Hinrichs, 1927.

- and H. Junker, "Die Sechs Teile des Horus Auge und der Sechste Tag,” Ztschr. Agypt. Spr., 48: 101-106, 1911.

Nazmi, A. A., La Médicine en Temps des Pharaons, Montpellier, Charite, 1903.

Neugebauer O., "Uber den Scheffel und Seine Teil," Ztschr. Ägypt. Spr., 65: 42-48, 1930.

Pacha, A., Ancienneté et Phénomènes Speciaux de Quelques Plantes de l'Egypt, Cairo, Imp. Nat., 1898, 14 pp.

Peacock, G., Life of Thomas Young, M. D., F. P. S., London, Tohn Murray, 1855, xiii + 514 pp., Chapter X, "Hieroglyphical Researches," pp. 258-344.

Peet, T. E., The Rhind Mathematical Papyrus: British Museum 10057 and 10058, Introduction, Transcrition. Translation and Commentary. University of Liverpool Press, 1923, 136 pn.

The Present Position of Egvptological Studies, An Inaugural Lecture Delivered before the Universitv of Oxford on 17 January 1934, Oxford, Clarendon Press, 1934, 22 pD.

Petrie, W. M. F., "Ancient Historical Weights and Measures." Encyclonedia Britannica, 11th Ed., Vol. 28: pp. 480-488, Cambridge, England, 1911.

, Ancient Weights and Measures Illustrated by the Egyttian Collection in Universitv College, London, Dept. of Egvptology, Univ. College, London, 1926, vi + 51 pp., 54 pl.

- Objects of Daily Use in Old Egypt: with over 1800 Figures from University College, London, London, British School of Archaeology in Egypt, Univ. College, B. Quaritch, 1927, 75 pp. + LXII pl.

- Stone and Metal Vases (of Old Egypt), London, Brit. School of Egyptian Archaeology, Univ. College, 1937, 35 pp. + XLI pl.

Ranke, H., "Medicine and Surgery in Ancient Egypt," Bull. Inst. Hist. Med., 1: 237-257, 1933. 
Reisner, G. A., The Hearst Medical Papyrus: Hieratic Text in 17 Facsimile Plates in Collotype with Introduction and Vocabulary, Leipzig, J. C. Hinrichs, 1905, vii +48 pp. +17 pl. Ridgeway, W., The Origin of Metallic Currency and Weight Standards, Cambridge, Univ. Press, 1892, xii + 417 pp.

Seth, K., Von Zahlen und Zahlworter bei den Alten Aegypten, Strassburg, Trübner, 1916, $155 \mathrm{pp}$.

Sigerist, H. E., A History of Medicine, Vol. I, Primitive \& Archaic Medicine, New York, Oxford Univ. Press, 1951, xxi+564 pp. Sobley, G. P. G., "An Eighteenth Dynasty Measure of Capacity," J. Egypt. Arch., 10: 283-284, 1924.

Sollman, T., "Dragon's Blood," J. Amer. Pharmaceut. Asso., 19: 141-144, 1920.

Speiser, E. A., "Some Sources of Intellectual and Social Progress in the Ancient Near East," in Studies in the History of Culture, Conference of Secretaries of the American Council of Learned Societies, Menasha, Wisc., 1942, pp. 51-62.

Spiegelberg, H., "Zu dem Spezialistentum in der Aegyptischen Medizen," Ztschr. Aegypt. Spr., 53: 111-118, 1917.

Steuer, R. O., Über des "Wohlriechende Natron" bei den Alten Agyptern: Interpretation Darstelling und Kultur des swtr, Leiden, E. J. Brill, 1937, 120 pp.

63: 279-284, 1943.

Egyptian Medicine," Suppl.Bull. Hist. Med., No. 10, Baltimore, Johns Hopkins Press, 1948, 36 pp.

Temkin, O., "Recent Publications on Egyptian and Babylonian Medicine," Bull. Inst. Hist. Med., 4: 247-256, 1936.

Thompson, E. M., "Papyrus," Encyclopedia Britannica, 11th Ed., Cambridge, 1911, 20: 743-745.

Trevan, J. W., "The Error of Determination of Toxicity," Proc. Roy. Soc. London, Ser. B., 101: 483-514, 1927.

Walker, J., Egyptian Sculpture from the Gulbenkian Collection, National Gallery of Art, Smithsonian Institution, Washington, D. C., 1949, 71 pp.

Wilson, J. A., The Burden of Egypt: An Interpretation of Ancient Egyptian Culture, University of Chicago Press, 1951, 332 pp.

Wreszinski, W., Der Grosse Medizinische Papyrus des Berliner Museums (Pap. Berl. 3038) in Facsimile und Umschrift mit Übersetzung, Kommentar und Glosser, Leipzig, J. C. Hinrichs, 1909, xxi +142 pp. 
Der Londoner Medizinische Papyrus (Brit. Museum Nr. 10059) und der Papyrus Hearst, in Transkription, Übersetzung und Kommentar, Leipzig, J. C. Hinrichs, 1912, xix +237 pp. Der Papyrus Ebers: Umschrift, UUbersetzung und Kommentar, Leipzig, J. C. Hinrichs, 1913, lv + 228 pp.

Young, T., Hieroglyphical Essays and Correspondence, Vol. 3 of Miscellaneous Works, ed. J. Leitch, London, John Murray, 1855,427 pp. 


\section{Index}

Abscesses, remedies for, 59, 80

Acacia, 39, 69

Accumulations, drugs to expel, 40, 84

Adams, F., 44, 98

Agreement on standards, 33

A 'h-mose, 31

Albright, W. F., 4

Alum, 42

Anal diseases, prescriptions for, 16, 59,78

Anal specialists, 16

Analysis of Egyptian medical papyri, $7 \mathrm{ff}$.

Animal bites, prescriptions for, 37, $55,59,96$

Animal remedies, 43, 72

Anise, 69

Arthritis, 62

Asiatic disease, 64, 91

Astringent drugs, 60

Balances for weighing, 20

Barley, 20, 70

Beans, 70

Beatty, Chester, 16

Beer, 42, 55, 73

Berkeley, California, 48

Berlin Medical Papyrus, 8, 14ff., 29, 32

Beverages, as vehicles, 42, 73

Bites, prescriptions for, 37, 55, 79

Blood, 43, 79

Blood vessels, treatise on, 12

Boils, prescriptions for, 59,88

Body odor, remedies for, 63,80

Bones, mending of broken, 39, 79, 94

Breasted, J. H., v, 9, 98

Burns, 52, 81

Capacity measurement, $19 \mathrm{ff}$.

Carminative drugs, 69

Case history, Kahun Papyrus, 8

Cases in Ebers Medical Papyrus, 12

Cases in Edwin Smith Papyrus, $10 \mathrm{ff}$.

Casts for fractures, 61

Castor plant as remedy, 70

Champollion, J. F., 4, 98

Cinnamon, 70

Clendening, L., v, 8, 10, 98

Constipation, 58

Contusions, prescriptions for, 52, 59, 85

Copper, 42

Coriander, 41, 69

Cosmetic recipes, $10,54,63$

Cubit, 18

Cumin, 41, 69

Cuppy, W., 3, 98

Cutaneous ailments in Hearst Papyrus, 60

Dandruff, 51,63

Dates as remedies, 71

Dawson, W. R., 74, 98

$d b n$ (Egyptian weight), 20

Degeneration of Egyptian medicine, 36

Demoniacal etiology, $34 \mathrm{ff}$.

Determinatives of Egyptian terms, 36

Diagnosis in Edwin Smith Papyrus, 10

Dioscorides, $44 \mathrm{ff}$.

Diseases in Hearst Papyrus, $57 \mathrm{ff}$., $78 \mathrm{ff}$.

Diseases, remedies for various, $41 \mathrm{ff}$.

Diseases, unidentified, 65

Dose-effect relation of drugs, $29 \mathrm{ff}$.

"Dragon's blood," 45, 73

Dropsy, 58, 64

Drug action, 29

Drug measurement, $20 \mathrm{ff}$., $28 \mathrm{ff}$.

Drugs, animal, 43, 72

Drugs, mineral, 42, 72

Drugs, miscellaneous, 43, 73

Drugs, plant, $41,68 \mathrm{ff}$.

Drugs, resinous, 42,72

Drugs, unidentified, 42, 71

Dynasty, XVIIIth, 22, 78

Dynasty, XXth, 16

Ebbell, B., 12, 99

Ebers, G., 12, 99

Ebers Medical Papyrus, 7 ff., 12 ff., 28,32

Edwin Smith Surgical Papyrus, v, 7 ff.

Egyptian Medical Papyri, table of, 7

Egyptians, old, 4, 34

Egyptologists, vii, 3

Empirico-rational medicine, 3, 40 
Epilepsy, 37

Erman Papyrus, 7, 14

Etiological factors, 61

Euphrates, 4

Evans, H. M., 48

Evil, prescriptions for expelling, 54, 58

Excrements in recipes, 43

Eye of Horus (symbol for measures), 20, 26

Fat, 43,73

Fever, 37, 55

Figs, 70

Fingers, prescriptions for, 54, 91

Formulary, old Egyptian physician's (Hearst Papyrus), 13

Formularies, mediaeval and English, 44

Fractures, treatment of, 61

Frankincense, 41, 72

Fulton, J. F., v, 99

Gardiner, A. H., 4, 16, 74

Garlic, 38, 70

Gifford, E. W., 48

Glanville, S. R. K., 3, 99

Glosses in Edwin Smith Papyrus, 11

Gourds as remedies, 42, 69

Grains for weighing, 20

Grapow, H., 7, 16, 35, 99

Greeks, 32

Griffith, F. Ll., 5, 18, 21, 23, 100

Gulbenkian Collection, 23

Hair, prescriptions for, 89

Hayes, W. C., 6, 100

Hearst Egyptian Expedition, 47

Hearst Medical Papyrus, v ff., 13 ff., 28, $47 \mathrm{ff}$.

Hearst, Mrs. Phoebe Apperson, 47

Heart, treatise on, 12

Heart disease, 58, 82

Hemorrhage, 54

Herget, H. M., 6, 100

Hieratic writing, 5

Hieroglyphics, $4 \mathrm{ff}$.

Hippocratic medicine, 39

hk.t (Egyptian 1/2 peck), 21, 23 ff.

hnw (Egyptian pint), 20 ff.

Honey, 42, 73

Horus eye, 20, 25, 65

Hyder, C. K., viii

Hyksos Period, 27, 31

Identification, difficulty of, $36 \mathrm{ff}$.
Incantations, 36

Indexing, need for, 50

Infants, diseases of, 14

Ingredients of Hearst Papyrus prescriptions, $68 \mathrm{ff}$.

Insect bites, 51

Institute for Advanced Study, vi

Internal diseases in Hearst Papyrus, 57,59

Invocations in Hearst Papyrus, 25, 55,94

Isis, 26

Joints, diseases of, 57, 62

Jonckheere, F., 16, 100

Juniper berries, 70

Kahun Obstetrical Papyrus, 7 ff., 31

kd.t (Egyptian weight), 24 ff., 60

Larkey, S. V., vi, 43, 49, 57

Leek, 38

Length, measures for, 19

London demotic papyrus (3rd Century A.D.), 32

London Medical Papyrus (1300 B.C.), $7,15,32$

Loret, V., 74

Lucas, A., 31, 100

Luckhardt, A. B., 9

Lutz, H. F., vi, 49, 100

Magico-religious medicine, 3

Major, Ralph, vii

Materia medica, 44

Measuring utensil, 25

Medical papyri, $7 \mathrm{ff}$.

Mesue, 44

Metropolitan Museum, N.Y., 22

Milk, 42, 73

Mineral remedies, 42

Möller, G., 26, 101

Moldy bread crumbs, 52

Mouthful (ro), $20 \mathrm{ff}$.

mspn.t, recipes for, 54,90

$m t . w$, prescriptions for, 53,85

Muscles, diseases of, 61

Myrrh, 42, 72

Nails, finger and toe, 54

Natron, 72

Neterhotep (old Egyptian physician), 16

Neugebauer, O., vi, 101

New York Academy of Medicine, 9 
New York Historical Society, 8

Nile, 3

Nose, broken, 10

nsj.t, 37, 55, 58, 93

Oil, 55, 73

Ointment, ibr, 74

Opium, 72

Oppenheimer, J. R., vi

Organization in Ebers Medical Papyrus, 12

Organization in Edwin Smith Surgical Papyrus, 10

Organization of Hearst Papyrus, $50 \mathrm{ff}$.

Orthopedic conditions in Hearst Papyrus, 57, 79, 94

Pains, prescriptions for, 70,80

Papyrus, general, 5

Peas, 70

Peet, T. E., 23, 101

Petrie, F., 21, 27, 101

Pharmacopeias, 44

Pharmacy, 41

Pharmacology, 32

Pharmaglen, vi

Plant remedies, 41,68

Pliny, 5

Polypharmacy, 41

Poppy, 72

Poultices, 39, 53, 65, 66, 70, 71

Prayers, 17, 50, 94

Prescriptions in Ebers Medical Papyrus, 12

Prescriptions of Hearst Papyrus, $51 \mathrm{ff}$., $78 \mathrm{ff}$.

Princeton University, vi

Prognosis in Edwin Smith Papyrus, 10

prs, 45

Purgatives, 58

Pus in Egyptian etiology, 61

Quantitation in old Egyptian prescriptions, 29 ff.

Rameses II, 32

Ranke, H., 35, 101

Recipes of Hearst Papyrus, $51 \mathrm{ff}$.

Recital for measuring utensil, 25

"Recital," origin of term, 36

Recitals in Ebers Medical Papyrus, 12

Recitals in Edwin Smith Papyrus, 10

Recitals in Hearst Papyrus, 25, 50, $55,64,83,94$
Reisner, G., 14, 47 ff., 102

Remedies, animal, 43, 72

Remedies, mineral, 42, 72

Remedies, miscellaneous, 43, 73

Remedies, plant, 41, 68

Remedies, resinous, 42, 72

Rhind Mathematical Papyrus, 23 ff.

Ridgeway, W., 18, 102

ro (Egyptian volume measure), $20 \mathrm{ff}$.

Rosetta stone, 4

Salt as remedy, 42,72

Saunders, J. B. deC. M., 39

Scribes of old Egypt, 5

Scroll, 6

Seth (Egyptian god), 26

Sethe, K., 48, 102

Sigerist, H., 3, 7, 25, 102

Skin ailments in Hearst Papyrus, 57, 60

Skin contusions, 52

Smith, E., 8

Sodium carbonate, 72

Sollmann, T., 46, 102

Soot as a remedy, 43, 73

Specialism in old Egyptian medicine, 16,57

Spieser, E. A., 4, 102

Spoons, $21 \mathrm{ff}$.

Standards for measurement, 33

Steding, Mary Jane, viii

Steuer, R. O., 60 ff., 67, 102

Stomach disorders, 81

Styrax, 38

Supernatural etiology and treatment, 34

Surgical conditions, 34

Surgical Papyrus, $8 \mathrm{ff}$.

Swellings, prescriptions for, 88

Table-spoon (ro), $21 \mathrm{ff}$.

Technical terminology, 10

Teeth, remedies for, 63,78

Temkin, O., 35, 102

Texts, Kahun, Smith and Ebers Papyri as, 13

Therapeutics, ancient Egyptian, 34 ff.

Thompson, E. M., 5

tmj.t, remedies for, 63

Toes, prescriptions for, 54, 91

Toxicity of drugs, 32

Translation, problems of, $36 \mathrm{ff}$.

Trevan, J. W., 32, 102

Ulcers, 54 
Unidentified diseases, 65

Unidentified remedies, 42, 71

University of California, v, 47

University of Kansas, vii

Urinary disorders, prescriptions for, 58,82

Utensil, measuring, 25, 55

Uterine conditions, 8

Vehicles, beverages as, 42, 73

Veterinary portion Kahun Papyrus, 8

$V$ is medicatrix naturae, 77

Wax, 43, 73

Weights and measures, $18 \mathrm{ff}$.
Weight standards, 19 ff.

whdw, Egyptian etiological principle, 61,67

Wheat, 20, 42

whi, remedies for, 66,79

Williams, Marjorie D., vi

Wilson, J. A., 3, 102

Wine, 42, 73

Wounds, 59

Wreszinski, W., 12, 49, 102

Young, T., 4, 103

Zaubersprüche für Mutter und Kind, 14 